\title{
SELECTED EXAMPLES OF STRUCTURE DETERMINATION OF NATURAL GAROTENOIDS
}

\author{
Synnøve LiaAen-Jensen \\ Organic Chemistry Laboratories, Norwegian Institute of Technology, Trondheim, Norway
}

\begin{abstract}
Selected examples of novel types of carotenoids studied in the author's laboratory during the past three years are discussed; including structural elucidation, total synthesis and biosynthetic considerations.

Carotenoids of photosynthetic bacteria, particularly the aryl ketone okenone and cross-conjugated carotenals of the rhodopinal series, $\mathrm{C}_{50^{-}}$ carotenoids of non-photosynthetic bacteria like dehydrogenans-P439, sarcinaxanthin, bacterioruberin and related compounds and $\mathrm{C}_{45^{-}}$and $\mathrm{C}_{50^{-}}$ carotenoids from Corynebacterium poinsettiae are considered. Glycosidic carotenoids from blue-green algae comprising myxoxanthophyll, oscillaxanthin and related glycosides and glycosidic carotenoids of bacterial origin are dealt with. Comments on fungal carotenoids are made. From higher plants the structures of lycoxanthin and an apo-carotenoid are treated. Finally carotenoids of lower marine animals, the acetylenic 'asterinsäure' and nor-carotenoids with ring contraction like actinioerythrin and the blue violerythrin are discussed.
\end{abstract}

\section{INTRODUCTION}

Considerable progress has been made in the structural elucidation of natural carotenoids during the three years following the first carotenoid symposium. Rather than present another general progress review ${ }^{1}$, I have chosen to discuss in rather more detail structure determination of selected examples of novel types of carotenoids studied in our own laboratory during the past three years.

From 1958 and onwards our general research programme has comprised chemical structure and biosynthesis of carotenoids in organisms of various evolutionary levels. We started with studies on photosynthetic bacteria and have gradually extended our studies to more highly developed organisms. In this paper recent examples from photosynthetic and non-photosynthetic bacteria, blue-green algae, fungi, higher plants and lower marine animals will be discussed.

\section{PHOTOSYNTHETIC BACTERIA}

Considerable attention has already been paid to the carotenoids of photosynthetic bacteria ${ }^{2-6}$, known to produce some forty specific carotenoids, which are generally aliphatic or aromatic in nature. Methoxylated carotenoids are still restricted to these organisms?. In order to localize our particular topic Figure 1 gives a summary of experimentally proved $3,8,9$ and postulated biosynthetic pathways. 


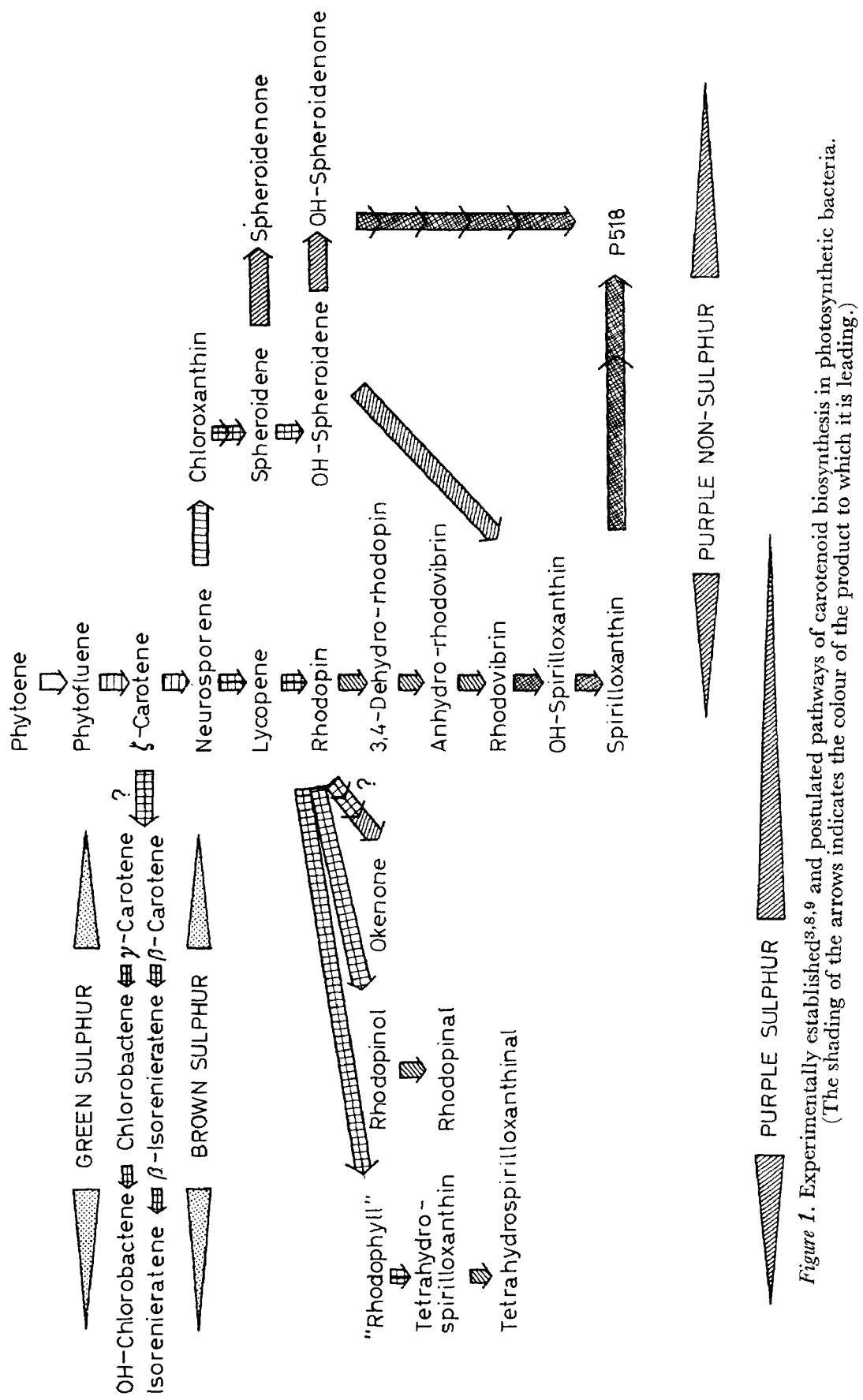




\section{STRUCTURE DETERMINATION OF NATURAL GAROTENOIDS}

The normal spirilloxanthin pathway comprising aliphatic carotenoids with tertiary hydroxy and methoxy groups occupies a central position common to both Athiorhodaceae and Thiorhodaceae species $^{3,6}$. The alternative spirilloxanthin pathway and the corresponding keto-series established for some Rhodopseudomonas sp. are given in the column to the right $^{3,9}$. Spirilloxanthin and its violet $2,2^{\prime}$-diketo-derivative ${ }^{10}$ are the terminal products.

The two other types of carotenoids characteristic of Thiorhodaceae, the rhodopinal series ${ }^{6,11}$ and possibly also okenone ${ }^{6,12}$, may be derived in vivo from lycopene.

The aliphatic precursor of the aryl-carotenoids ${ }^{13,14}$ of the green bacteria is not yet established, and is possibly neurosporene.

We shall here consider the structures of okenone and the rhodopinal type carotenoids.

\section{Okenone}

Okenone is the characteristic carotenoid of the goliath of the photosynthetic bacteria, Chromatium okenii ${ }^{15}$. It is a conjugated ketone with one 1,2,3-trimethylphenyl and one methoxylated end group, Figure 2. Its structure was deduced from the spectroscopic properties of okenone itself and various derivatives ${ }^{16}$. The structure was subsequently confirmed by total synthesis of okenone and of three derivatives prepared from natural okenone $^{12}$. This work has recently been reviewed ${ }^{17}$.

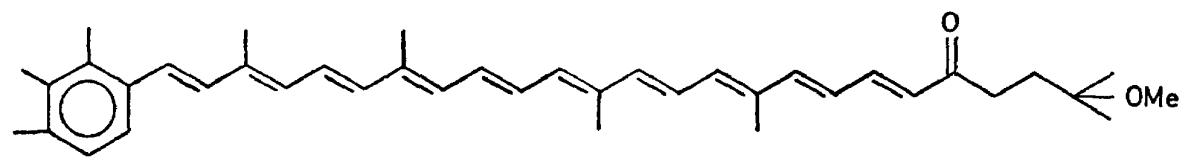

Figure 2. Okenone ${ }^{12}$.

It is assumed, but not experimentally proved, that the 1,2,5-trimethylphenyl end group is formed in vivo by dehydrogenation and methyl migration of a common $\beta$-type end group ${ }^{13,18,19}$. 1,2,3-Trimethyl substitution could possibly be explained by isomerization of the 1,2,5-trimethyl derivative via an intermediary Ladenburg prism structure, Figure 3. Analogies are known from photochemical isomerization of substituted benzene

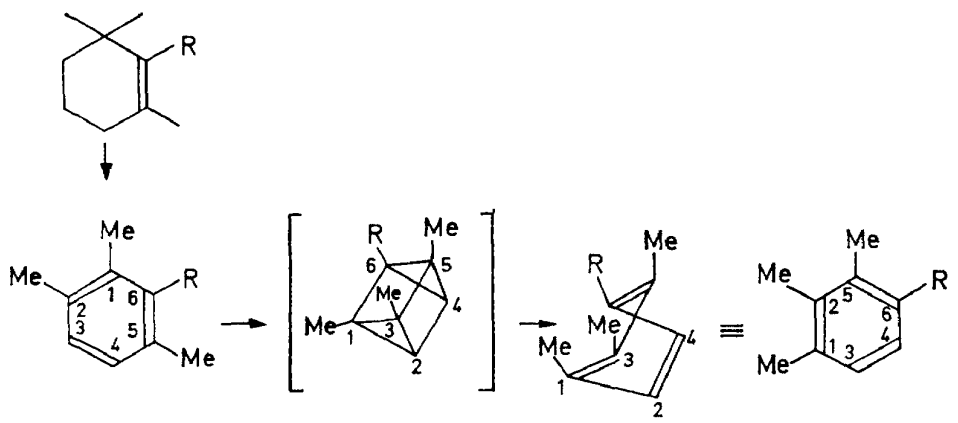

Figure 3. Hypothetical in vivo synthesis of aryl carotenoids. 
derivatives ${ }^{20,21}$. Experimental studies on the biosynthesis of aryl carotenoids, which are not likely to follow the common shikimic and acetate pathways ${ }^{22}$, are needed.

\section{Rhodopinal series carotenoids}

The complete structures of the carotenoids of the rhodopinal series have only recently been revealed and are chemically the more interesting ones. The broad and unusual absorption spectrum of rhodopinal, previously called warmingone ${ }^{23}$, was for some time a puzzle. p.m.r. spectroscopy provided the clue to these structures ${ }^{11}$ and unpublished mass spectrometric studies $^{24}$ have permitted more precise structural proposals, Figure 4.

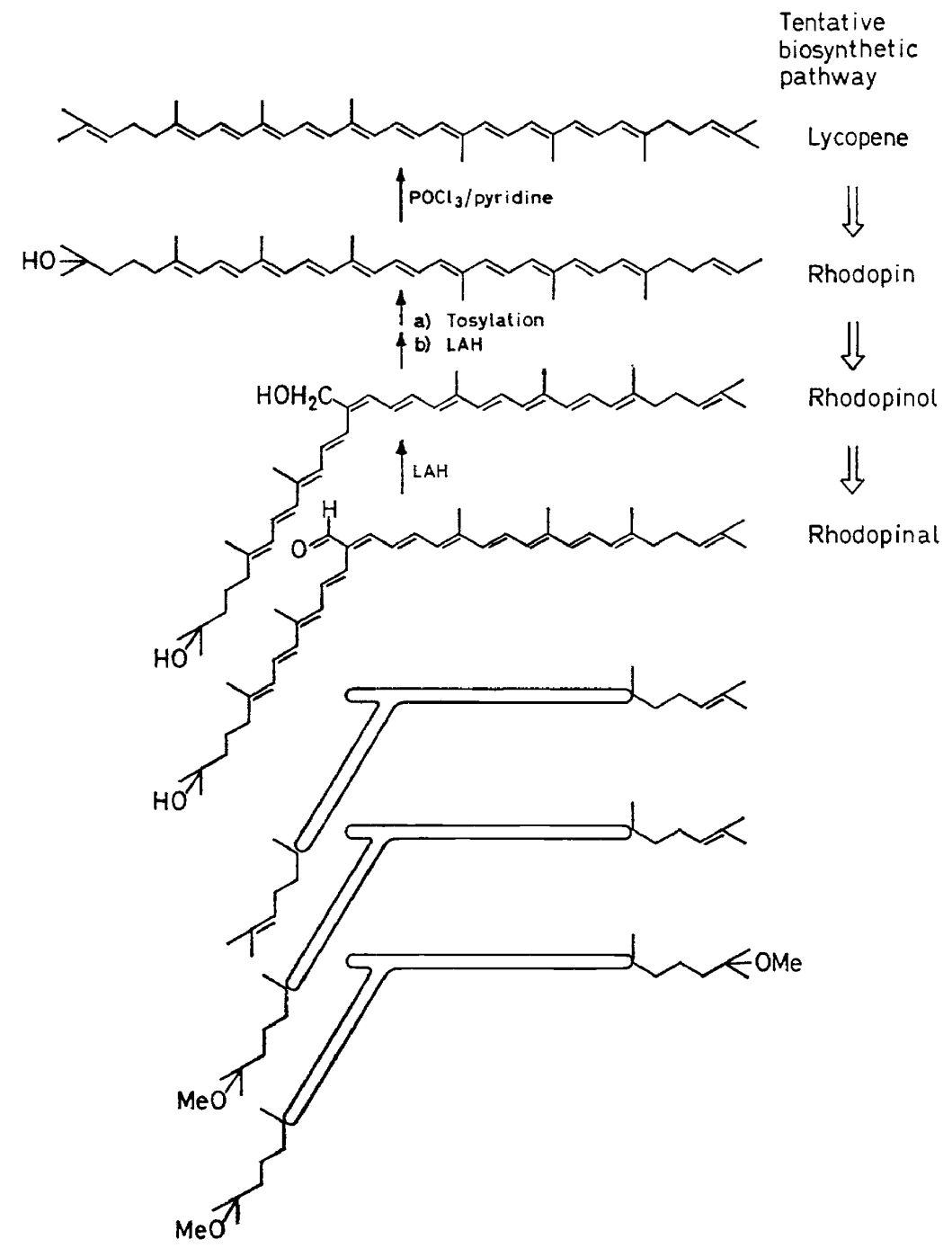

Figure 4. Structures, chemical transformation and postulated biosynthetic route of the carotenoids of the rhodopinal series ${ }^{11,24}$. 
The carbonyl-containing compounds of the series are cross-conjugated carotenals where the 20-methyl group is formally oxidized to an aldehyde. This structural modification causes cis-configuration of the neighbouring double bond. The angular shaped molecule may partly be the reason why these carotenoids do not crystallize.

Rhodopinal is the key member of this series. It occurs together with the corresponding allylic alcohol rhodopinol, rhodopin and lycopene ${ }^{23,11}$. Chemically rhodopinal was reduced to rhodopinol by lithium aluminium hydride $^{23}$. Rhodopinol tosylate was further converted to rhodopin by hydride reduction $^{11}$ and rhodopin may in turn be dehydrated to lycopene by phosphorus oxychloride in pyridine ${ }^{13}$. The chemical transformation sequence is thus the reverse of the postulated biosynthetic sequence. We have also isolated the corresponding lycopenal ${ }^{23,11}$ and the mono-24 and dimethoxy ${ }^{11}$ derivatives. The latter occurred together with $3,4,3^{\prime}, 4^{\prime}$-tetrahydro-spirilloxanthin, the structure of which was proved by total synthesis ${ }^{25}$.

Rhodopinal exhibits an aldehyde signal in the p.m.r. spectrum and provides aldehyde derivatives such as the acetal, oxime and dinitrophenylhydrazone. From the $100 \mathrm{Mcs}$ p.m.r. spectrum of the last-named the aldehyde group could be allocated to the $19,20,19^{\prime}$ or $20^{\prime}$-position. Cross-conjugation was also required to account forthe absorption spectrum in visible light ${ }^{11}$. Mass spectrometric evidence ${ }^{24}$ further permits the choice of the 20-position, that is on the same side of the molecule as the tertiary hydroxyl or methoxyl substituent. In particular the observed in-chain fragmentations (not yet confirmed by high precision measurements) lead to this assignment. Ions ascribed to eliminations from the polyene chain and corresponding to the M-92, M-106 and M-158 ions of common carotenoids ${ }^{26-28}$ confirm the hetero substituent on the polyene chain, Figure 5.

With Figure 6 comments will be made on the absorption spectra of this type of cross-conjugated carotenoid ${ }^{11}$. The figure shows the absorption spectra in visible light measured in acetone solution of various derivatives of tetrahydrospirilloxanthinal - the dinitrophenylhydrazone $\mathrm{A}$, the aldehyde itself $\mathrm{B}$, the oxime acetate $\mathrm{C}$, the oxime ether $\mathrm{D}$, the oxime $\mathrm{E}$, and the allylic alcohol F. According to an empirical rule by Zechmeister the location of the cis-peak in carotenoid spectra should be at $c a .142 \pm 2 \mathrm{~m} \mu$ shorter wavelength than the maximum at longest wavelength of the trans isomer ${ }^{29}$. The different cross-conjugated hetero substituents on the polyene chain change the main absorption region in a manner rather to be expected. However, the location of the cis-peak is constant in all these derivatives and coincides with that of the allylic alcohol. This is taken as a demonstration of at least two active chromphores in these cross-conjugated carotenoids-the cis-undecaene chromophore being active in all of them. In hexane solution a double set of 'cis-peaks' is distinguished in the rhodopinal spectrum. These 'cis-peaks' are further accentuated in the low-temperature spectrum, Figure 7. The scope and limitation of low-temperature spectra of carotenoids for stereochemical problems will be discussed elsewhere ${ }^{30}$.

Only the allylic alcohols of these series could be partly isomerized to the all-trans isomers, a fact that has led us to postulate that hetero substituents on the polyene chain in analogous cases can be revealed by the tendency of the compound in question to possess cis-configuration ${ }^{11}$. 


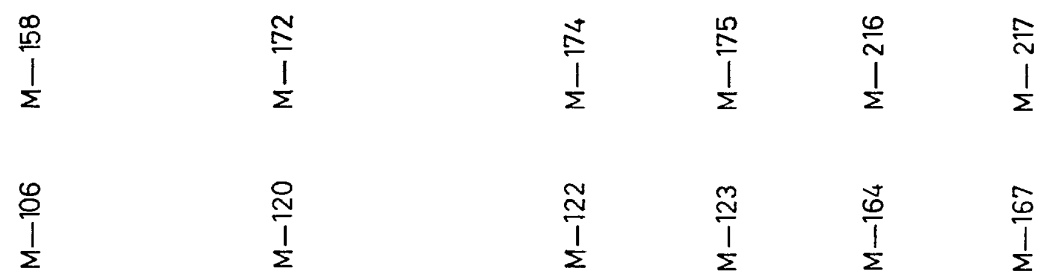

$\stackrel{1}{2}$

$\frac{\mathscr{0}}{\frac{1}{\Sigma}}$

$\frac{\infty}{\frac{1}{2}}$

$\stackrel{0}{\stackrel{1}{1}}$

$\frac{\text { 是 }}{\frac{1}{2}}$

$\frac{\stackrel{n}{?}}{\frac{1}{2}}$

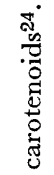

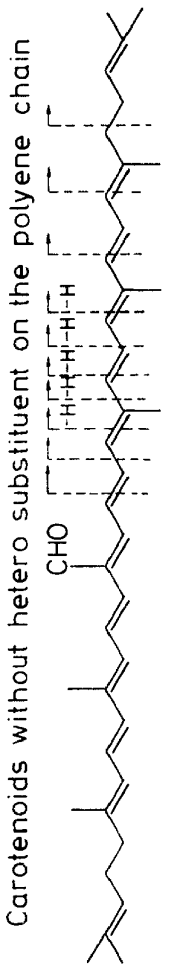

<

$y \quad y$

y

y

y

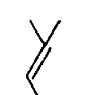

.

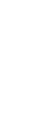




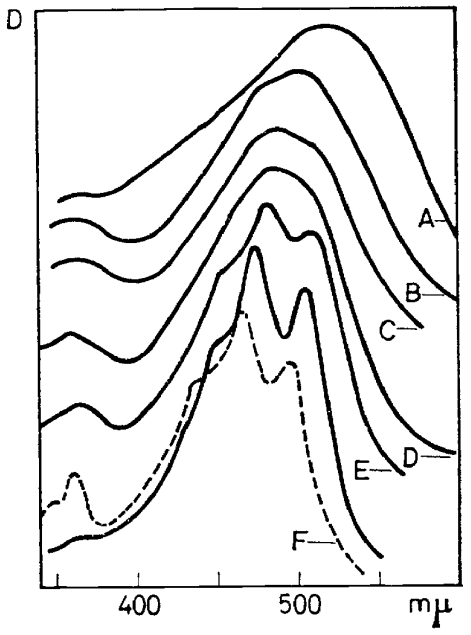

Figure 6. Absorption spectra in visible light of various derivatives of $3,4,3^{\prime}, 4^{\prime}$-tetrahydrospirilloxanthin-20-al in acetone. - stereoisomer absorbing at longest wavelength, - - - neo A. A 2,4-dinitrophenylhadrazone, B aldehyde, C oxime acetate, D oxime ether, $\mathrm{E}$ oxime, $\mathrm{F}$ allylic alcohol11.

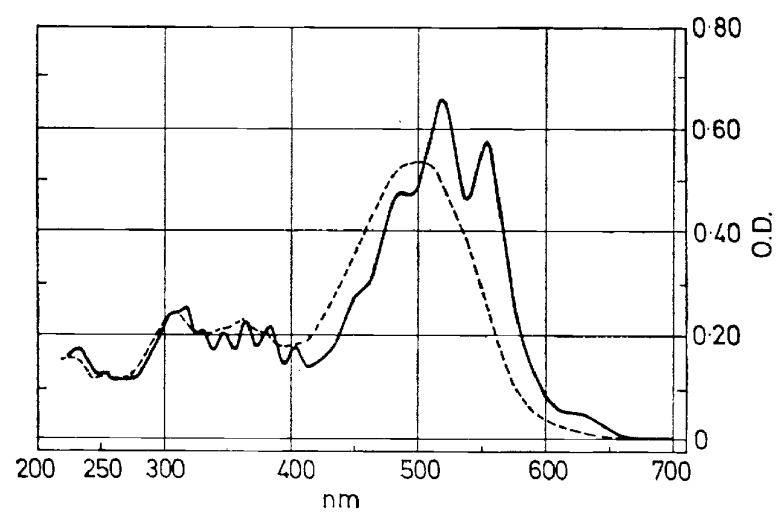

Figure 7. Absorption spectra in visible light of rhodopinal, recorded in EPA solution at - - - room temperature and liquid nitrogen temperature ${ }^{30}$.

We shall leave the photosynthetic bacteria at this point and turn to non-photosynthetic bacteria.

\section{NON-PHOTOSYNTHETIC BACTERIA}

\section{$\mathrm{C}_{50}$-carotenoids}

In addition to producing more traditional carotenoids non-photosynthetic bacteria are the only organisms which so far have revealed the ability to synthesize carotenoids with 50 -carbon skeletons.

Dehydrogenans- $\mathrm{P} 439$ from Flavobacterium dehydrogenans was the first representative of this class ${ }^{31}$. The detailed structure determination of this compound has been published ${ }^{32-34}$ and has recently been reviewed ${ }^{17}, c f$. Figure 8 . 
The observed loss of 140 mass units from the molecular ion of P439, explained by a retro-Diels-Alder rearrangement of the substituted $\alpha$-ring, gave the clue to its structure ${ }^{32}$. Sarcinaxanthin from Sarcina lutea had been identified with dehydrogenans-P43935. However, on isolation of crystalline sarcinaxanthin and further characterization ${ }^{36}$ it has been found that this<smiles>C/C=C/C(C)=C/C=C/C(C)=C/C=C/C=C(C)/C=C/C=C/C=C(C)/C=C/C1C(C)=CCC(C/C=C/C(C)=C\CC2C(C)=CCC(CC=CC(C)CO)C2(C)C)C1(C)C</smiles>

Dehydrogenans-P439<smiles>CC(C)=CCC1CC=C(C)C(C=CC(C)=CC=CC(C)=CC=CC=C(C)C=CC=C(C)C=CC2C(CO)=CCC(CC=C(C)C)C2(C)C)C1(C)C</smiles>

\section{Sarcinaxanthin ?}

Figure 8. Dehydrogenans-P439 and sarcinaxanthin ${ }^{33,36}$.

important peak is lacking in the mass spectrum of sarcinaxanthin. The molecular composition of dehydrogenans- $\mathrm{P} 439$ and sarcinaxanthin is identical, and like P439 sarcinaxanthin gives a mono- and diacetate and $\alpha, \beta$-unsaturated mono- and dialdehydes. However, non-identity is evident from the crystalline shapes, melting points, and spectral data (i.r., p.m.r. and

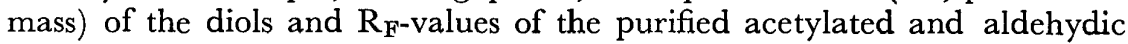
derivatives. Judged from comparative p.m.r. studies of the natural diols and mass spectral studies of the di(trimethylsilyl) ethers sarcinaxanthin appears to be non-symmetrical, and the evidence obtained is so far best accommodated with the structure given in Figure 8 for sarcinaxanthin ${ }^{36}$. The strongly polar xanthophyll of Sarcina lutea is possibly glycosidic ${ }^{37}$.

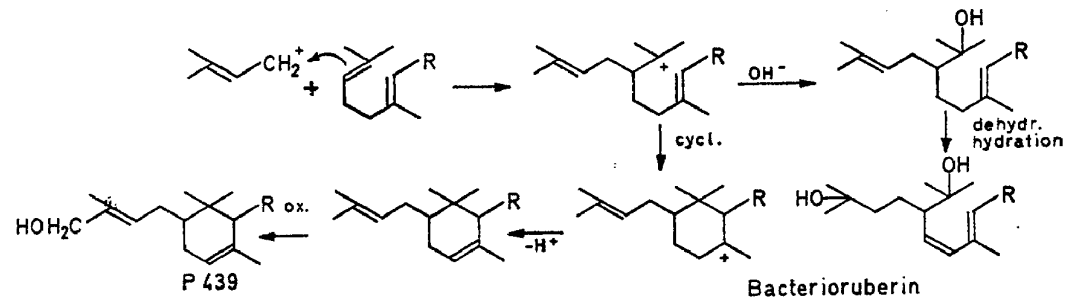

Figure 9. Hypothetic biosynthetic route to $\mathrm{C}_{50}$-carotenoids.

Biosynthetically (Figure 9) the P439 skeleton could be formed by addition of isopentenylpyrophosphate units to the isopropylidene double bond in a $\mathrm{C}_{40}$-skeleton and subsequent cyclization. Elimination of a proton would give the $\alpha$-ring characteristic of $\mathrm{P} 439^{33}$. Other bacterial carotenoids possess similar end groups with a $\beta$-ring, that is the double bond in the 5,6position $^{38}$. The same line of argument leads to the revised structure for 
bacterioruberin ${ }^{39}$ if one assumes addition of $\mathrm{OH}^{-}$to the tertiary carbonium ion and subsequent introduction of a double bond in 3,4-position and hydration of the isopropylidene double bond.

Bacterioruberin is the main carotenoid of red, extremely halophilic bacteria. At a period when p.m.r. and mass spectra were not available it was considered to be the $\mathrm{C}_{40}$-diol, 1 , shown in Figure $10^{40}$, but was later found
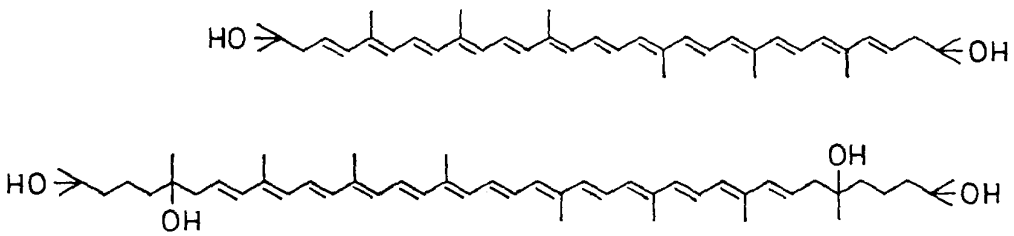<smiles>CCCCCCCCCCCC(C)(O)CCC(C)(O)CC=CC(C)=CC=CC(C)=CC=CC(C)=CC=CC=C(C)C=CC=CC(C)=CC=CC(C)(C)O</smiles>
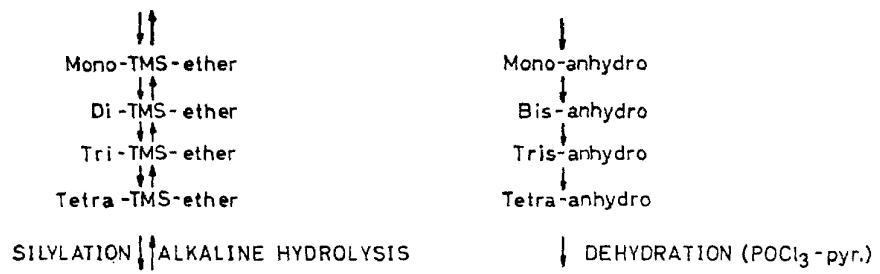

Figure 10. Bacterioruberin-reactions and alternative structures ${ }^{39,42}$.

to differ from that diol when it became synthetically available ${ }^{41}$. Mass spectrometry has now revealed that bacterioruberin is $\mathrm{C}_{50} \mathrm{H}_{76} \mathrm{O}_{4}$. All four oxygen functions are shown to be tertiary hydroxyl groups, demonstrated by negative acetylation and detailed studies of the course of trimethylsilyl ether formation to mono-, di-, tri- and tetra ethers and subsequent alkaline hydrolysis of these silyl ethers, and furthermore by the dehydration sequence with $\mathrm{POCl}_{3} /$ pyridine to the mono-, di-, tri- and tetra-anhydro derivatives ${ }^{39}$. p.m.r. data (lack of a doublet at $7 \cdot 70 \tau(J=7 \mathrm{cps})$ for allylic methylene groups, and the integral caused by methyl groups in saturated environment, 6 such methyl groups for the linear and 8 for the branched $\mathrm{C}_{50}$ structure) favours the branched alternative, 3, given in Figure 10.

The p.m.r. spectrum is in fact very simple-only one signal integrating for 6 in-chain methyl groups and another corresponding to 8 gem methyl groups in saturated surroundings, are observed in the methyl region. Recorded with larger expansion the two methyl groups with partly end-ofchain character give rise to a separate signal at $8.09 \tau$, and the two gem dimethyl groups tend to split into two signals of equal intensity at 8.79 and $8 \cdot 82 \tau^{42}$.

Preference for the branched structure, 3 , follows also from the mass spectrum. The tetraol structure is confirmed by losses of water, maximum four times, 
see Figure 11. Observed losses of 58 mass units, occurring no more than twice, can be accommodated by the branched structure but not readily by the linearly extended structure, $2^{24}$. Only the common losses of 92,106 and 158 mass units are derived by eliminations from the polyene chain, disfavouring any extra substituents on the polyene chain ${ }^{43,24}$.

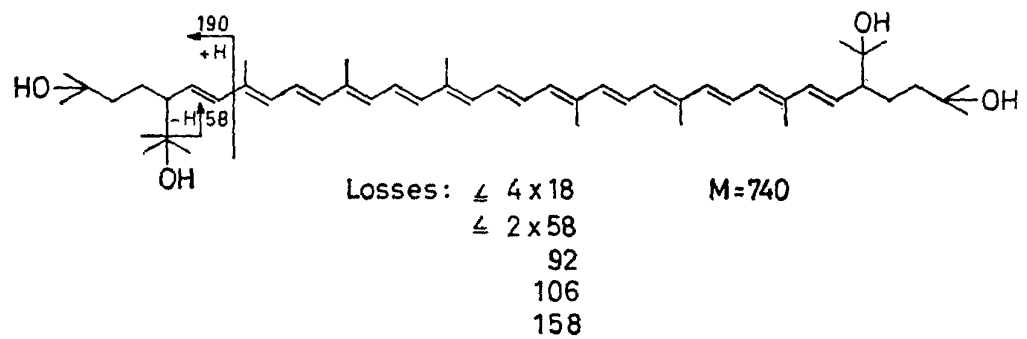

Figure 11. Mass spectrometric fragmentation of bacterioruberin ${ }^{42}$.

Two minor carotenoids isolated from Halobacterium salinarium are tentatively ascribed the structures given in Figure $12^{42}$. They have the same tridecaene chromophore and contain 3 and 2 tertiary hydroxyl groups respectively. Presence of an isopropylidene group in the triol is suggested from p.m.r. evidence. The same dihydroxy compound has recently been obtained in the pure, crystalline state from Corynebacterium poinsettiae, and p.m.r. and mass spectral data appear to agree with the structure given ${ }^{38}$.<smiles>CC(C)=CCC(/C=C/C(C)=C/C=C/C(C)=C/C=C/C(C)=C/C=C/C=C(C)/C=C/C=C(C)/C=C/C=C(C)/C=C/C(CCC(C)(C)O)C(C)(C)O)C(C)(C)O</smiles><smiles>CC(C)=CCC(/C=C/C(C)=C/C=C/C(C)=C/C=C/C(C)=C/C=C/C=C(C)/C=C/C=C(C)/C=C/C=C(C)/C=C/C(CC=C(C)C)C(C)(C)O)C(C)(C)O</smiles>

Figure 12. Minor carotenoids from Halobacterium salinarium ${ }^{42}$.

In Corynebacterium poinsettiae the $\mathrm{G}_{50}$-diol had previously been misidentified as spirilloxanthin ${ }^{45,7}$, see Figure 13 . The experience with bacterioruberin ${ }^{41,42,44}$ and its bis-anhydro-derivative ${ }^{45,7,38}$ serves to demonstrate the necessity of mass spectra in structural work on carotenoids. Moreover, comparative studies based on $\mathrm{R}_{\mathrm{F}}$-values and partition coefficients are greatly misleading on comparison of $\mathrm{C}_{40^{-}}$and $\mathrm{C}_{50^{-}}$-carotenoids. ${ }^{46,42} \mathrm{C}_{50}$-derivatives with the same chromophore and functional groups of course are less polar because of the 'dilution effect' of the larger carbon skeleton. 
<smiles>CC(C)=CCC(/C=C/C(C)=C/C=C/C(C)=C/C=C/C(C)=C/C=C/C=C(C)/C=C/C=C(C)/C=C/C=C(C)/C=C/C(CC=C(C)C)C(C)(C)O)C(C)(C)O</smiles><smiles>CCCCCCC(C)(C)OC</smiles><smiles>CC(C)=CCC1CCC(C)=C(/C=C/C(C)=C/C=C/C(C)=C/C=C/C=C(C)/C=C/C=C(C)/C=C/C2=C(C)CCC(C/C=C(\C)CO)C2(C)C)C1(C)C(C)(C)C</smiles><smiles>CC1=CC(O)CC(C)(C)C1</smiles>

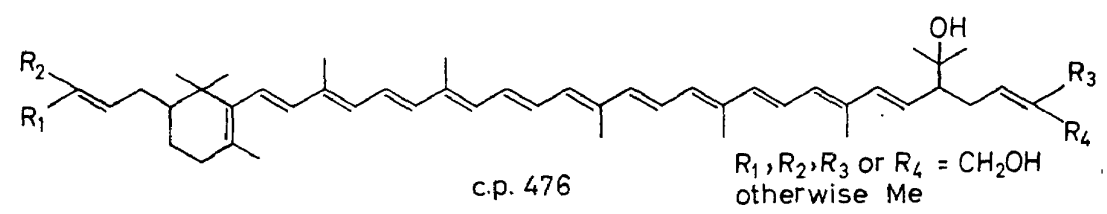<smiles>CCC=C(C)CCC=C(C)CO</smiles><smiles>CC(C)=CC=C(C=CC(C)=CC=CC(C)=CC=CC(C)=CC=CC=C(C)C=CC=C(C)C=CC=C(C)CCC=C(C)C)C(C)(C)O</smiles>

Figure 13. $\mathrm{C}_{30}$-carotenoids and a $\mathrm{C}_{45}$-carotenoid from Corynebacterium poinsettiae ${ }^{38}$.

Another compound from Corynebacterium poinsettiae previously tentatively identified with cryptoxanthin has $\beta$-carotene chromophore and two hydroxyl groups accessible for acetylation. It is different from cryptoxanthin ${ }^{7}$ and is chromatographically slightly less strongly adsorbed than zeaxanthin and isozeaxanthin. The bicyclic structure given in Figure 13 is assigned to this xanthophyll ${ }^{38}$. A carotenoid previously tentatively identified as lycoxanthin ${ }^{45}$ is different from lycoxanthin ${ }^{7}$ and has a monocyclic $\mathrm{C}_{50}$-structure ${ }^{38}$. Other minor carotenoids of $C$. poinsettiae are also under investigation ${ }^{38}$.

Starr and Saperstein ${ }^{45}$ made the interesting observation that the carotenoid synthesis of $C$. poinsettiae depended on the thiamine content of the medium. High thiamine concentrations promoted good growth and preferential formation of the zeaxanthin-like carotenoid, whereas low thiamine 
concentrations limited growth and resulted in preferential synthesis of the spirilloxanthin-like carotenoid. Intermediate thiamine concentrations gave the lycoxanthin-like carotenoid. It was inferred that thiamine was effecting the cyclization reaction-an inference that holds also on the basis of the

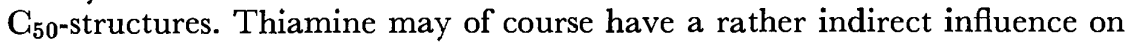
the carotenoid synthesis.

Since the postulated biosynthesis of $\mathrm{C}_{50}$-carotenoids involves addition of two $\mathrm{C}_{5}$-units to a common $\mathrm{C}_{40}$-skeleton, we have long suspected the existence of $\mathrm{C}_{45}$-carotenoids. The first crystalline $\mathrm{C}_{45}$-carotenoid was obtained from C. poinsettiae. The evidence obtained is in agreement with the structure given in Figure 13-an aliphatic xanthophyll with dodecaene chromophore and one tertiary hydroxy group-again with the extra $\mathrm{C}_{5}$-unit attached to 2-position.

In conclusion $\mathrm{C}_{50}$-carotenoids are presumably wide-spread in nonphotosynthetic bacteria. So far all representatives encountered in our laboratory appear to have the extra $\mathrm{C}_{5}$-units attached to $2,2^{\prime}$-positions of a traditional $\mathrm{C}_{40}$-skeleton.

\section{BLUE-GREEN ALGAE (AND NON-PHOTOSYNTHETIG BAGTERIA)}

\section{Glycosidic carotenoids}

The glycosidic character of strongly polar carotenoids from non-photosynthetic bacteria and blue-green algae has recently been recognised ${ }^{47-50}$.

The Ethiopian lake Aranguadi has provided most of our raw material of blue-green algae, since an Arthrospira sp. occurs in nearly pure culture there. From this Arthrospira sp. and other blue-green algae like Oscillatoria spp. ${ }^{51}$ and Aphanizomenon flos-aque 52 we have isolated well known carotenoids (Figure 14) like $\beta$-carotene ${ }^{51,52}$, cryptoxanthin ${ }^{51}$ and zeaxanthin ${ }^{51}$, shown
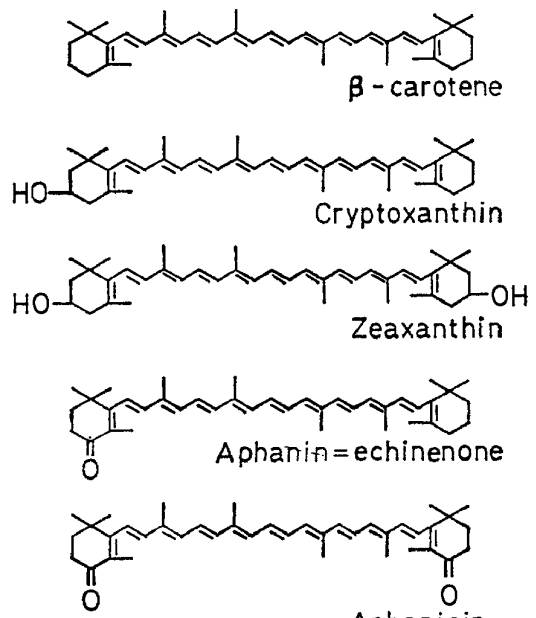

Aphanicin $=$ canthaxanthin

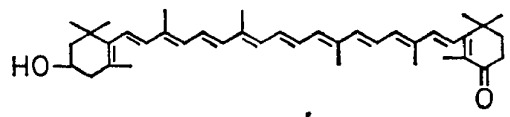

3-OH- $4^{\prime}-$ keto- $\beta$ - carotene

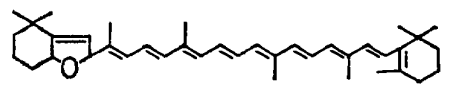

Flavacin = mutatochrome

Figure 14. Garotenoids from blue-green algae 51,52 . 
that crystalline aphanin is identical with echinenone ${ }^{52}$, crystalline aphanicin with canthaxanthin ${ }^{52}$ and flavacin with mutatochrome ${ }^{53}$. 3-Hydroxy-4'keto- $\beta$-carotene was a new, but structurally uninteresting compound ${ }^{51}$. Especially the structures of the characteristic blue-green algal pigments myxoxanthophyll and oscillaxanthin, given with partial structure in Figure 14 , have required some effort.

The structure of the strongly polar myxoxanthophyll was examined in the thirties by Heilbron's ${ }^{54}$ and Karrer's ${ }^{55}$ schools and then considered to be a $\mathrm{C}_{40}$-carotenoid. Mass spectrometry has now revealed that myxoxanthophyll is a $\mathrm{C}_{46}$-compound. We have unpublished evidence for the rhamnoside structure for myxoxanthophyll given in Figure $15^{48}$, drawn as an $\alpha$-L-
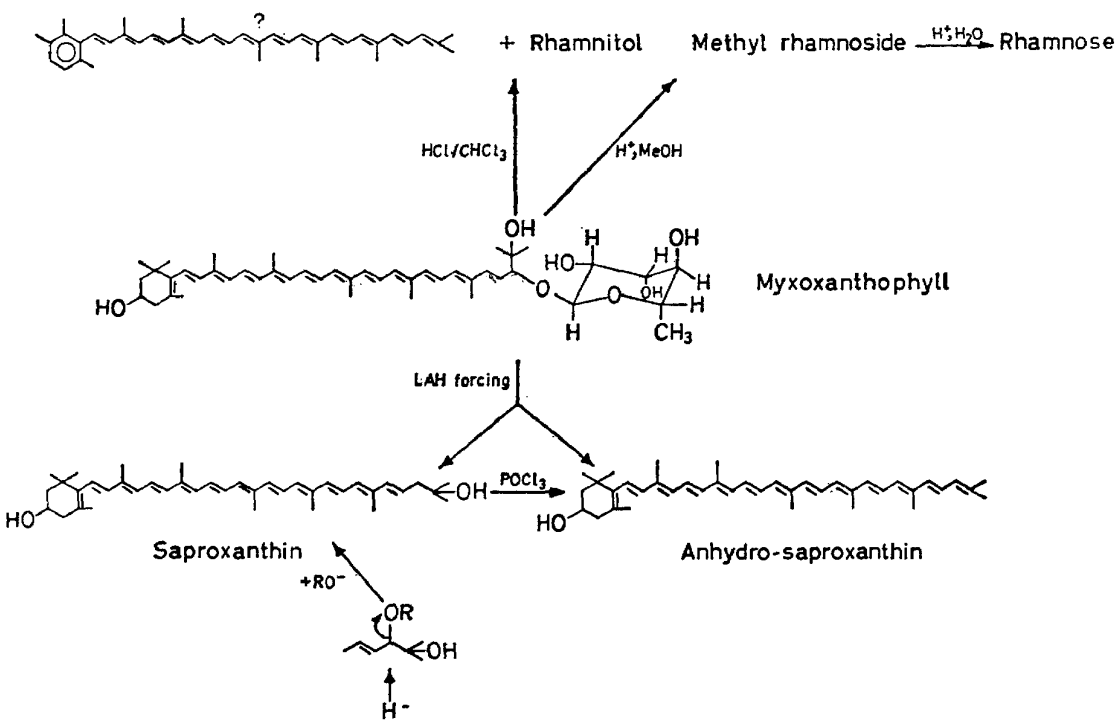

Anhydro-saproxanthin

Figure 15. Myxoxanthophyll-structure and some reactions ${ }^{48}$.

rhamnoside, although the stereochemistry is unknown and more likely $\beta$. The identification of the monocyclic aglycone is based on spectroscopic data (visible light, i.r., p.m.r. and mass spectra) and on isolation of the diol saproxanthin ${ }^{56}$ and its formal dehydration product on forcing hydride reduction. Hydride reduction was not expected to affect a compound of this structural type. The formation of saproxanthin may be explained by hydride attack in 2'-position, whereas the mechanism for the formation of the elimination product is not understood. The saproxanthin produced in this reaction could be converted to the second product by dehydration with phosphorus oxychloride in pyridine. ${ }^{57}$ Myxoxanthophyll gives a tetraacetate on acetylation and the tetraacetate forms a mono(trimethylsilyl) ether, demonstrating the presence of four primary or secondary hydroxyl groups and one tertiary hydroxyl group in myxoxanthophyll. Treatment of myxoxanthophyll with hydrogen chloride in dry chloroform resulted in rearrangements of the aglycone and in elimination of a sugar-like residue. In this reaction no reducing sugar, but a compound inseparable from the 


\section{SYNNØVE LIAAEN-JENSEN}

methyl-pentitol rhamnitol was isolated. The identification was based on gas chromatographic (as per-trimethylsilyl ether) and paper chromatographic comparison. However, hydrolysis in acid methanol gave a different reaction, and led to the isolation of reducing rhamnose after hydrolysis of the methyl rhamnoside first formed.

The carotenoid elimination product in the $\mathrm{HCl}-\mathrm{CHCl}_{3}$ reaction had absorption properties and stereomutation behaviour (stereoisomeric sets comprising apparently same 4 stereoisomers) suggestive of identity with $3^{\prime}, 4^{\prime}$-didehydro-chlorobactene. The question mark reveals our scepticism since in vitro aromatization of carotenoids has hitherto not been reported.

The olefinic and methyl regions of the p.m.r. spectra of myxoxanthophyll peracetate and of plectaniaxanthin ${ }^{58,59}$ (the aglycone of myxoxanthophyll lacking the 3-hydroxy substituent) support identical polyene chains and carbon skeletons in the two compounds. Myxoxanthophyll peracetate exhibits in addition signals associated with the rhamnose moiety.

Figure 16 indicates the electron-beam induced fragmentation of myxo-
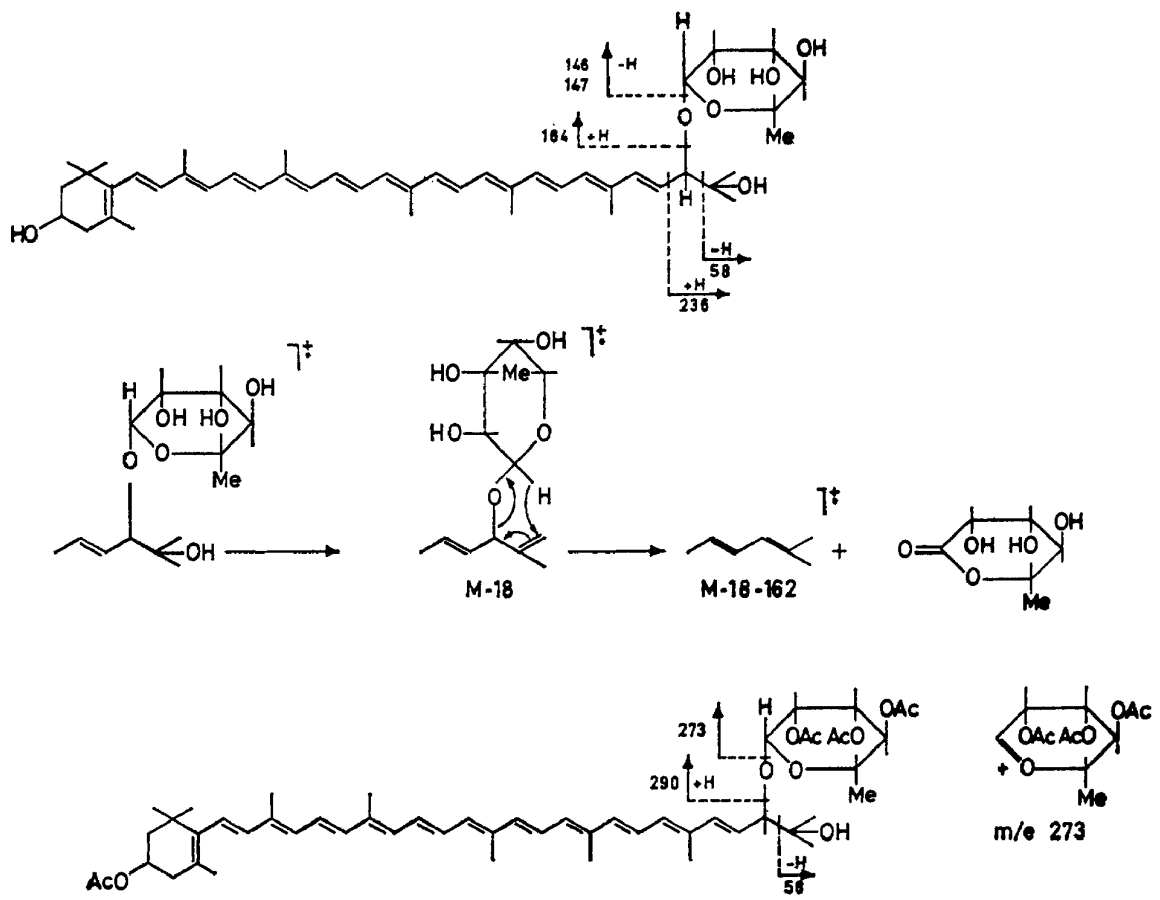

$m / e 273$

Figure 16. Electron-beam induced fraginentation of myxoxanthophyll and its tetraacetate ${ }^{48}$.

xanthophyll and the tetraacetate, with molecular ions at $\mathrm{m} / \mathrm{e} 730$ and 898 respectively. Both compounds give the characteristic carotenoid losses of $\mathbf{9 2}$ (toluene) and 106 (xylene) derived from the polyene chain, and other losses including these fragments. The tetraacetate loses acetic acid in the expected manner. In both compounds the spectra are dominated by peaks caused by fragmentation of the aliphatic end groups carrying the glycoside residues. 
Loss of 58 mass units (acetone) in both compounds demonstrates the presence of the aliphatic end group. Loss of 180 mass units from the molecular ion of myxoxanthophyll could be explained by a two-step process--dehydration followed by expulsion of the sugar moiety with hydrogen transfer to the carotenoid ion. M-146, M-147, M-164 and M-236 ions in the spectrum of myxoxanthophyll are attributed to the indicated cleavages with hydrogen transfer in the case of even-numbered ions. Analogous fragmentations (M-273 and $\mathrm{M}-290$ ) are observed for the tetraacetate. In the latter case cleavage of the glycosidic linkage results in preferential maintenance of the charge on the sugar moiety, giving rise to a prominent peak at $\mathrm{m} / \mathrm{e} 273$. The mass spectra revealed the presence of a minor hexose constituent in myxoxanthophyll, which although apparently chromatographically homogeneous is hence a mixed glycoside. The hexose is revealed in the acetate spectrum by a peak at $\mathrm{m} / \mathrm{e} 331$ corresponding to the oxonium ion and small peaks at $\mathrm{M}^{\prime}=956$, $\mathrm{M}^{\prime}-58, \mathrm{M}^{\prime}-92$ and $\mathrm{M}^{\prime}-106$. A weak peak at $\mathrm{m} / \mathrm{e}=746$ in the spectrum of myxoxanthophyll can also be seen. The presence of the hexose, presumably glucose, was confirmed by paper chromatography of the hydrolysate following glycoside hydrolysis ${ }^{48}$.

The pink oscillaxanthin has a related structure, again a rhamnoside with one end group common with myxoxanthophyll. Oscillaxanthin is the di-rhamnoside of a symmetrical tridecaene tetraol, Figure $17^{49}$. It is thus an

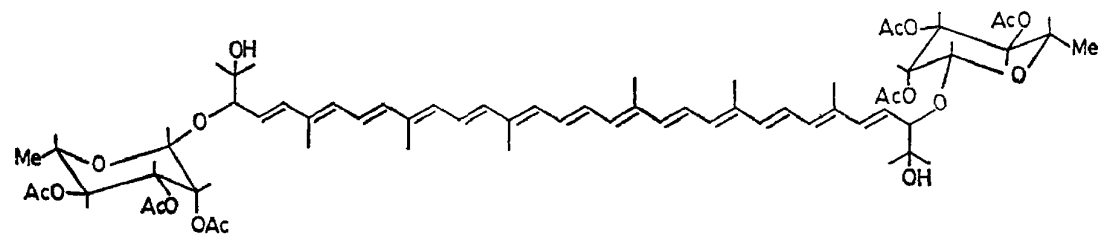

Figure 17. Oscillaxanthin ${ }^{49}$.

octa-ol with disagreeable polarity properties. The chemical reactions used in the structural elucidation parallelled those used for myxoxanthophyll, and the mass spectrum of the hexaacetate was again very informative. In the p.m.r. spectrum of the hexaacetate the gem dimethyl groups are, as in myxoxanthophyll, magnetically non-equivalent, due to molecular asymmetry of the neighbouring carbon atom ${ }^{60,61}$. Assuming that oscillaxanthin is an L-rhamnoside like other natural rhamnosides, tentative assignment of configuration follows from a comparative study of the ring proton and acetoxy region with model compounds ${ }^{62}$.

From Oscillatoria limosa we have recently isolated a myxoxanthophyll-like carotenoid which is a new glycoside with the aglycone in common with myxoxanthophyll, but with a methoxylated sugar residue ${ }^{63}$. Other carotenoid glycosides from $O$. limosa are still under investigation.

Figure 18 includes the structures of other known carotenoid glycosides. Crocin, the digentiobiose ester of crocin, is known from Karrer's early work ${ }^{64}$. Phlei-xanthophyll and 4-keto-phlei-xanthophyll are tertiary Dglucosides of bacterial origin ${ }^{47}$, and the most recent example, a methyl apolycopenoate derivative isolated from a yellow halophilic bacterium, 

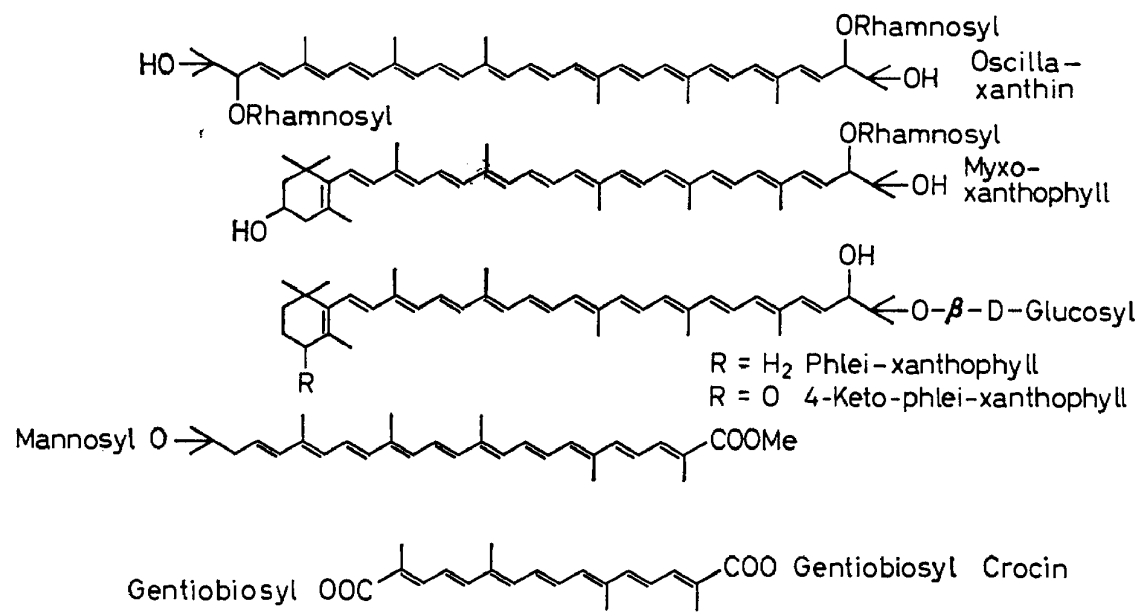

Figure 18. Known carotenoid glycosides.

appears to be a mannoside ${ }^{50}$. In this case the prominent peaks in the lower part of the mass spectrum of the peracetate, Figure 19, confirmed the hexose formulation. The scheme is that of Biemann et al. ${ }^{65}$ and the relative intensities of the various ions for our bacterial glycoside are given in parenthesis. The

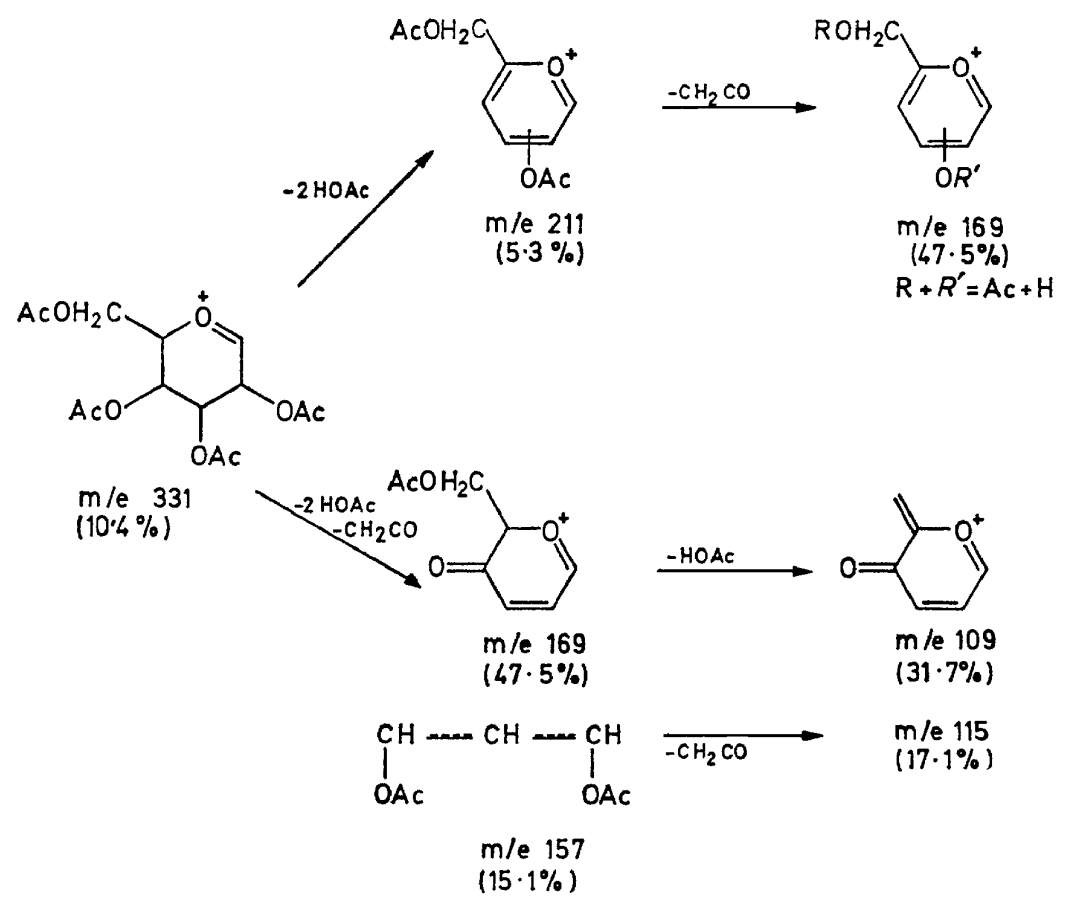

Figure 19. Fragmentation of tetraacetoxy oxonium ions according to Biemann et al.65 and observed peak intensities in the mass spectrum of tetraacetoxy methyl 1-hexosyl-1,2-dihydro3,4-didehydro-apo-8'-lycopenoate ${ }^{50}$. 


\section{STRUGTURE DETERMINATION OF NATURAL CAROTENOIDS}

mass spectrum of the natural glycoside further agrees with the structure suggested-diagnostically useful fragments are indicated in Figure 19. The decaene polyene chain follows from the visible light absorption spectrum of the allylic alcohol obtained on lithium aluminium hydride reduction. A trisubstituted double bond, rather than a disubstituted one, $\alpha$ to the carboalkoxy function is supported by infrared evidence. Disubstituted double bonds in $\alpha$-position to carboalkoxy, carboxyl and keto groups have been found to causesplitting of the out-of-plane $\mathrm{CH}=\mathrm{CH}$ deformation vibration in the $960 \mathrm{~cm}^{-1}$ region, a useful observation for structural work on apo-carotenoids ${ }^{66}$. Some other chemical reactions are indicated in Figure 20. Strong

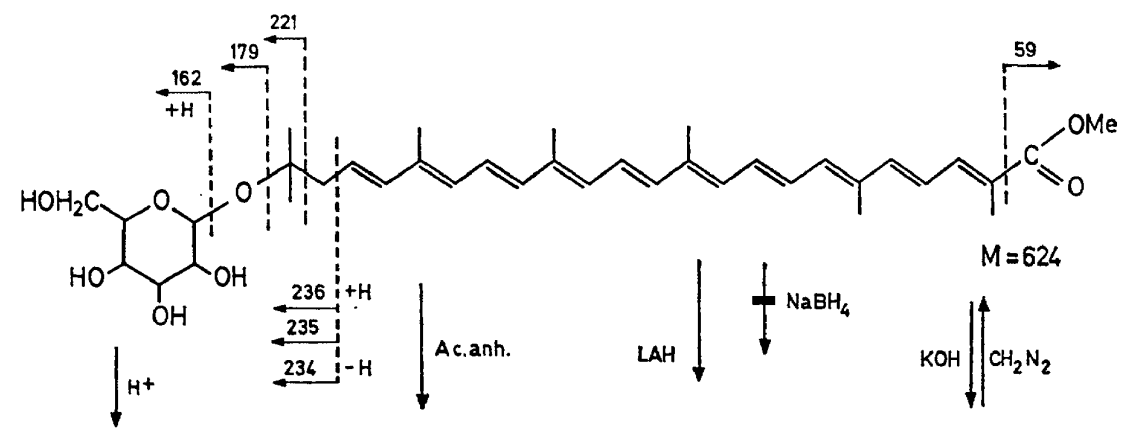

Reducing sugar

$R_{F}=$ mannose

Tetraacetate

Allylic alcohol

Carboxylic acid

Figure 20. Methyl 1-hexosyl-1,2-dihydro-3,4-didehydro-apo-8'-lycopenoate-structure and reactions ${ }^{50}$.

alkaline hydrolysis provides the free acid which is methylated with diazomethane to a product indistinguishable from the natural methyl ester. Glycoside hydrolysis gave a reducing sugar with $\mathrm{R}_{\mathrm{F}}$-value like mannose $\mathrm{e}^{50}$.

When the carotenoid chemist in search for more challenging structural problems concentrates on highly oxygenated carotenoids it appears that he is likely to end up doing sugar chemistry on a glycoside. The hydrolysis conditions required for isolation of the sugar generally means sacrificing the aglycone. For introductory studies, mass spectrometry of the peracetate is the method of choice.

\section{FUNGI}

From fungi we have isolated an apo-carotenoic acid ${ }^{67}$, an apo-carotenoic ester $^{68}$ and esters of tertiary carotenols ${ }^{58,69}$. The Sarcoscyphaceae synthesize keto carotenoids with structures similar to those of the keto series of the Athiorhodaceae (Figure 1), except that tertiary esters are produced rather than tertiary methyl ethers 58,69 .

Terpenoid compounds with terminal methylene groups are common, Figure 21. This structural element has not yet been encountered in natural carotenoids. Introductory studies of a new carotene from fungal source studied in collaboration with French co-workers indicate that a terminal methylene group may be present. This carotene, $\mathrm{C}_{40} \mathrm{H}_{56}$, is isomeric with the common carotenes $(\alpha-, \beta-, \gamma-, \delta-, \epsilon \text {-carotene and lycopene })^{\mathbf{7 0}}$. 
<smiles>C=C(C)C1CCC(C)CC1</smiles>

Limonene<smiles>C=C1CCCC(C)(C)C1/C=C/C(C)=O</smiles>

$\gamma$-Ionone<smiles>C=CC(=C)CCC=C(C)C</smiles>

Myrcene

Figure 21. Examples of terpenoids with terminal methylene groups.

\section{HIGHER PLANTS}

Turning to higher plants, we have recently revised the structures of lycoxanthin and lycophyll isolated from the red berries of Solanum dulcamara ${ }^{71}$. Lycoxanthin and lycophyll were previously considered to be lycopene hydroxylated in the traditional $3,3^{\prime}$-positions ${ }^{72}$, but are now shown to be primary allylic alcohols where one of the isopropylidene methyl groups is formally oxidized - the same situation as in dehydrogenans-P43933. The p.m.r. spectroscopy was of decisive importance. The methyl and methylene proton signals for lycoxanthin acetate are included in Figure 22. Hungarian workers ${ }^{73}$
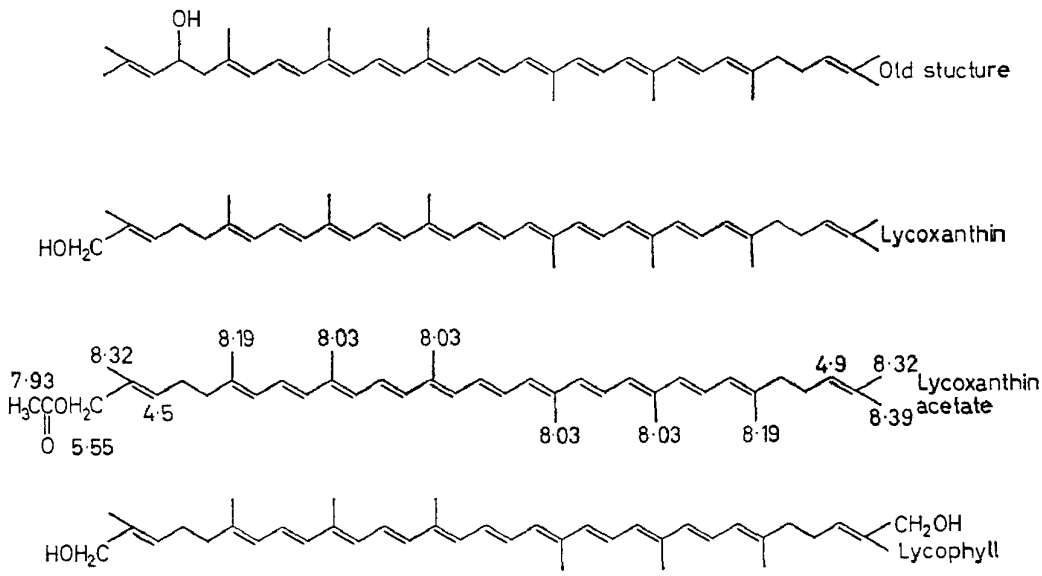

Figure 22. Lycoxanthin and lycophyl171.

arrived independently at the same conclusion. The indicated trans stereochemistry of the hydroxylated end group is not yet established. We intend to investigate it by the same method as used for the terminal end group of dehydrogenans-P43934.

A small scale total synthesis of lycoxanthin tetrahydropyranyl ether has been achieved according to the scheme outlined in Figure 2374 based on the reaction of levulinaldehyde (obtained on ozonolysis of methyl heptenone) with ( $\alpha$-carboethoxy-ethylidene) triphenyl phosphorane. The keto group was protected by ketal formation and the ester group reduced to the primary alcohol, which was protected as tetrahydropyranyl ether. The carbon skeleton was extended by two carbon atoms by a Horner reaction with 

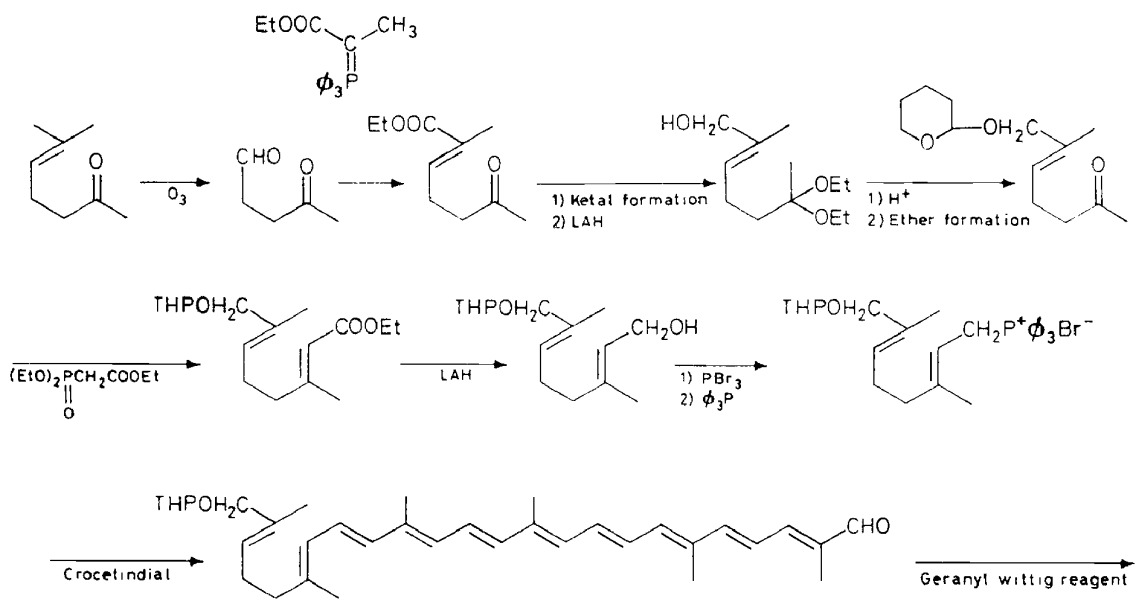<smiles>CC(C)=CCCC(C)=CC=CC(C)=CC=CC(C)=CC=CC=C(C)C=CC=C(C)C=CC=C(C)CCC=C(C)CO</smiles><smiles>CC(C)=CC=CC(C)=CC=CC=C(C)C=CC=C(C)C=CC=C(C)CCC=C(C)C</smiles><smiles>CCOC(=O)C(C)=CCCC(C)=CC=CC(C)=CC=CC(C)=CC=CC=C(C)C=CC=C(C)C=CC=C(C)C</smiles>

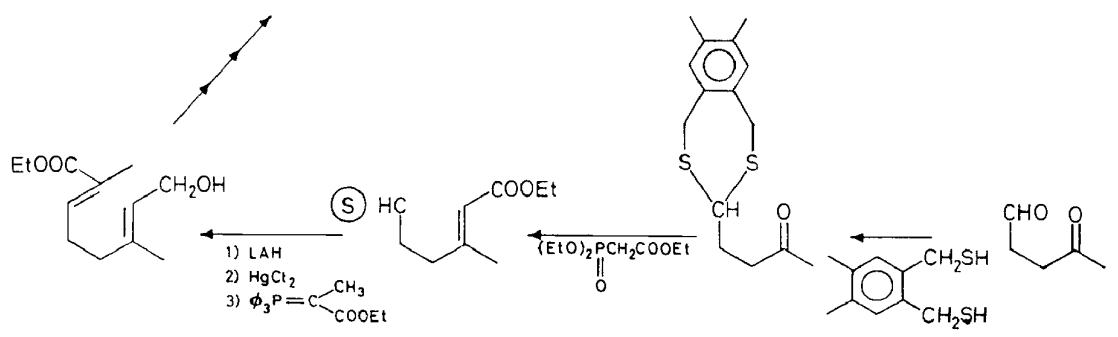

Figure 23. Synthesis of lycoxanthin ${ }^{74}$.

triethylphosphonoacetate after removal of the ketal group. The further conversions to the Wittig salt and reaction with crocetindial and geranylidene triphenylphosphonium bromide followed standard methods. The tetrahydropyranyl ether could not be hydrolysed under conditions where the carotenoid survived. We are presently pursuing an alternative method based on a thioacetal of levulin aldehyde followed by chain elongation by 
two carbon atoms at the keto group and subsequently by Wittig reaction of the regenerated aldehyde with ( $\alpha$-carboethoxy-ethylidene)tri-phenyl phosphorane; the ester function will be reduced at the carotenoid stage.

A major carotenoid present in Shepherdia canadensis had been claimed to be lycoxanthin acetate ${ }^{75}$, but was found to be the new methyl apo- $6^{\prime}$ lycopenoate ${ }^{76}$ by spectral evidence and degradation studies to the free acid, the allylic alcohol and the aldehyde, Figure 24 . This was subsequently proved

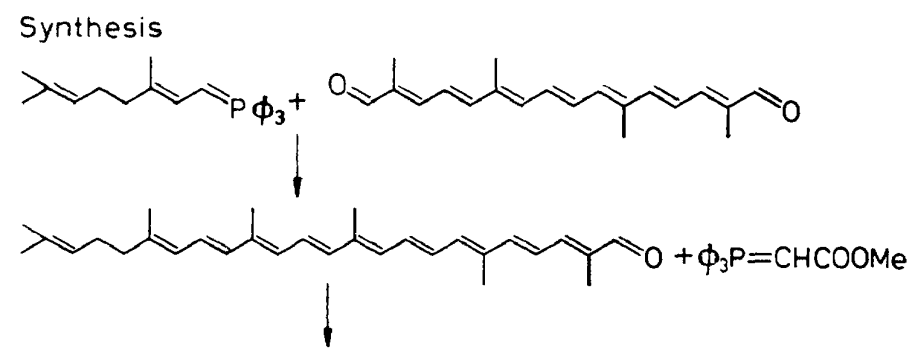

Degradation

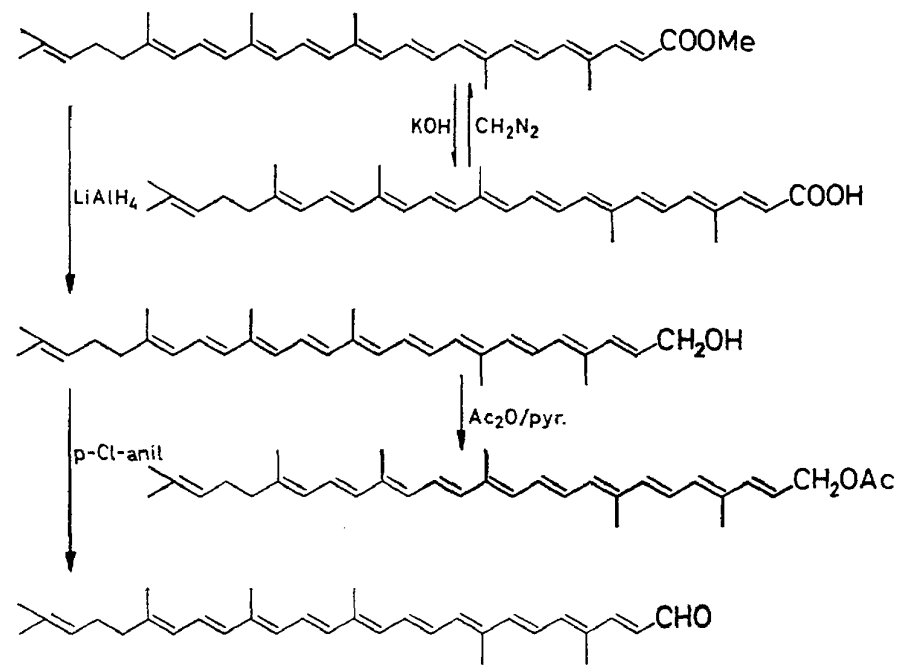

Figure 24. Reactions and synthesis of methyl apo- $6^{\prime}-$ lycopenoate. ${ }^{76}$

by synthesis by standard methods from geranylidene triphenyl-phosphonium bromide and crocetindial giving apo-8'-lycopenal which with carbomethoxymethylene-triphenyl phosphorane gave the natural ester.

A detailed comparison of the chemical shift positions of the methyl groups in unsubstituted, 3-hydroxy and 3-acetoxy $\beta$-rings has been found to be very useful for assignment of hydroxy groups to the relatively unreactive 3 -position 77,48 and was used to confirm the structure proposed by Kuhn's school for rubixanthin ${ }^{77}$, Figure 25. 

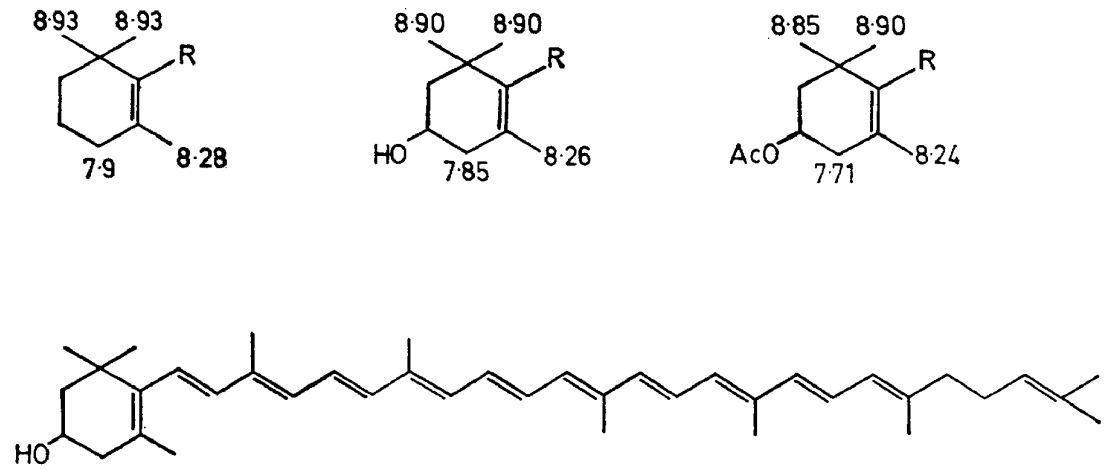

Rubixanthin

Figure 25. The p.m.r. assignments of substituted $\beta$-rings and structure of rubixanthin 7 .

\section{LOWER MARINE ANIMALS}

\section{Acetylenic carotenoids}

Acetylenic carotenoids have more been a speciality of other research groups $^{78-80}$. However, we have shown that asterinsäure ${ }^{81}$ is a monoacetylenic derivative of astaxanthin, or possibly a mixture of the mono- and diacetylenic compounds ${ }^{82}$, Figure 26 . The latter alternative has been confirmed in an unpublished re-investigation ${ }^{83}$. Whereas the stretching frequency of the disubstituted triple bond is weak in other acetylenic carotenoids so far studied, it represents a strong band in asterinsäure because of the neighbouring keto group ${ }^{48}$.<smiles>C/C=C/C=C(C)/C=C/C(C)=C/C=C/C(C)=C/C=C/C=C(C)/C=C/C=C(C)/C=C/C1=C(C)C(=O)C(O)CC1(C)C</smiles><smiles>CC1=C(C)C(C)(/C(C)=C/C=C(C)/C=C/C(C)=C/C=C/C(C)=C/C=C/C=C(C)/C=C/C=C(\C)C#CC2=C(C)C(O)C(O)C(C)(C)C2(C)C)CC(O)C1=O</smiles>

Figure 26. Astaxanthin ${ }^{92}$ and asterinsäure ${ }^{82,83}$. 


\section{Nor-carotenoids with ring contraction}

The last topic brings me to the latest extension of the carotenoid conception. By the previous definition carotenoids were yellow or red pigments ${ }^{85}$, but must now also include blue ones. The carotenoid to be discussed, actinioerythrin, is obtained from the sea anemone Actinia equina, and was first studied by Lederer's ${ }^{86}$ and Heilbron's ${ }^{87}$ schools in the thirties.

We 88,89 now consider actinioerythrin to be a $2,2^{\prime}$-bisnor-astaxanthin diester with $\mathrm{C}_{38}$-skeleton, and thus the first example of a nor-carotenoid with ring contraction. The key reactions leading to its structure are given in Figure 27. Careful treatment with sodium borohydride reduces the two

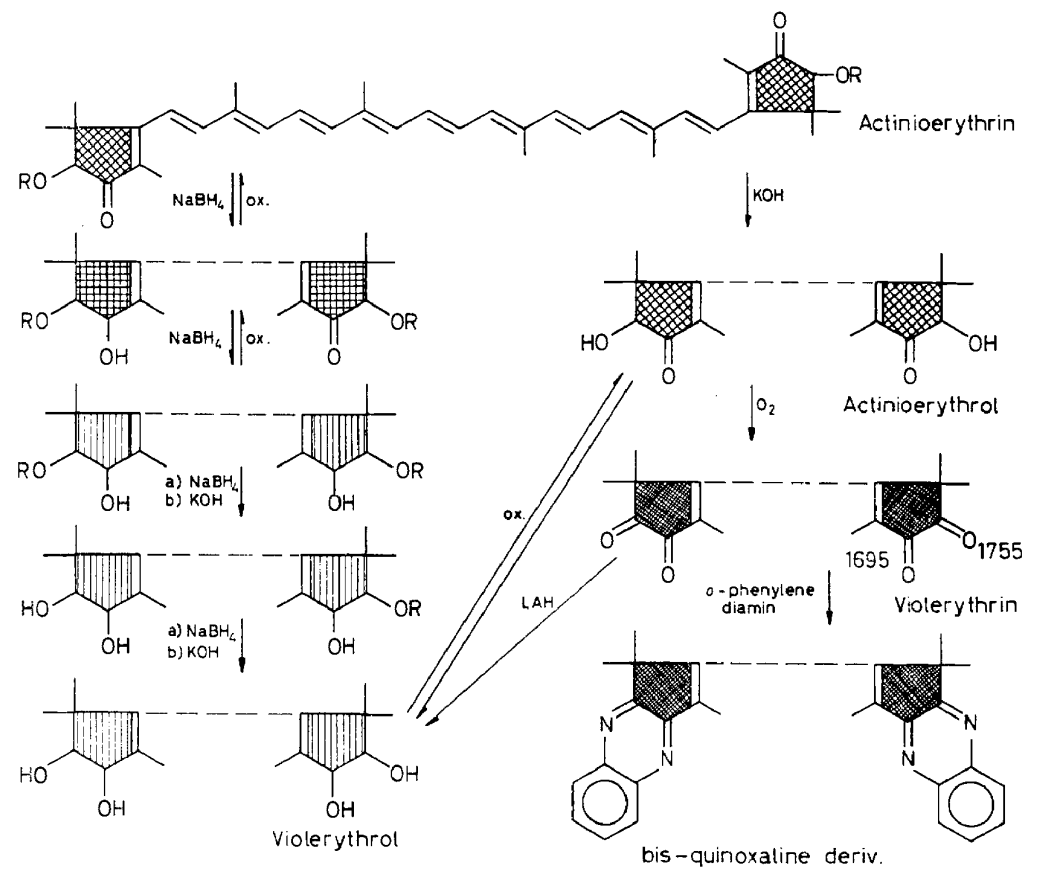

Figure 27 . Key reactions in the structure determination of actinioerythrin 88,89 .

keto groups to a mono- and a diol, which by hydrogenolysis or saponification of the ester groups provide respectively a triol and a tetraol, designated violerythrol. Alkali treatment of actinioerythrin leads via the intermediary $\alpha$-ketol, actinioerythrol, in the presence of oxygen to the blue tetraketone violerythrin, which reacts smoothly with $o$-phenylene-diamine to a bisquinoxaline derivative in accordance with reported data for simple cyclopentenedione derivatives ${ }^{90}$. Hydride reduction of violerythrin gives the tetraol violerythrol which on oxidation with oxygen in the presence of iodine ${ }^{91}$ gives the $\alpha$-ketol actinioerythrol. Acetylation studies of all hydroxy derivatives confirm the number of hydroxy substituents in each case. The molecular weight is confirmed by mass spectrometry for violerythrol, actinio-erythrol diacetate, violerythrin and its bisquinoxaline derivative. 


\section{STRUGTURE DETERMINATION OF NATURAL CAROTENOIDS}

The observed fractionation pattern is in agreement with these structures, and has been discussed elsewhere 89 . The p.m.r. spectrum of actinioerythrin furthermore reveals its 10 methyl groups. The carbonyl frequencies in the i.r. spectra of actinioerythrin and violerythrin are in agreement with data for related model compounds.

Judged from its mass spectrum and non-preparative chromatographic separation on paraffin-impregnated paper crystalline actinioerythrin is a mixture of some six esters to which the alcohol moiety, actinioerythrol, is common. The mass spectrum suggests that the two esterifying acids of the four major ester components together contain 17, 15, 13 and 12 carbon atoms. The esterifying acids have been examined as methyl esters by gas chromatography and mass spectrometry. Only methyl esters of capric $\left(\mathrm{C}_{10}\right)$, undecanoic $\left(\mathrm{C}_{11}\right)$ and lauric $\left(\mathrm{C}_{12}\right)$ acid were identified unambiguously; methyl caproate $\left(\mathrm{C}_{6}\right)$ tentatively by gas chromatography alone.

Non-enolized $\alpha$-diketones and cyclopentenedione derivatives are yellow compounds. The blue colour of violerythrin ${ }^{87}$ is thus explained by the strong chromophore of the end groups conjugated with the polyene chain. The absorption spectrum in visible light of actinioerythrin and actinioerythrol reveals near co-planarity of the cyclopentene ring and the polyene chain, in contrast to the situation for $\beta$-rings and 1,2,5-trimethylphenyl end groups where steric conflict between the 18-methyl group and the 8-hydrogen twists the $\beta$-ring out of the plane of the polyene chain ${ }^{1}$.

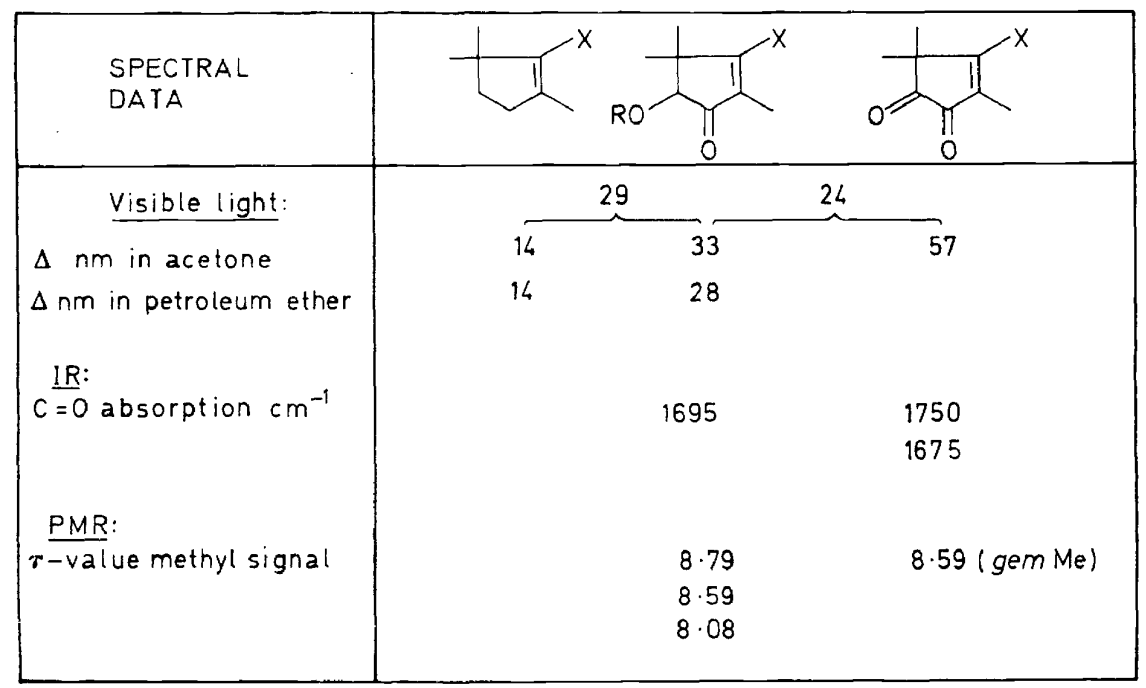

Figure 28. Spectral properties of cyclopentene, cyclopentenone and cyclopentenedione rings of nor-carotenoids.

Spectral data for these novel end groups are compiled in Figure 28. The spectral contribution of the trimethyl-cyclopentene double bond corresponds nearly to that of an aliphatic double bond, and that of the 4-keto group to the upper value of that of an aliphatic carbonyl group. The spectral contribution of the second carbonyl group is also considerable $(24 \mathrm{~nm}$ in 
acetone). The characteristic $\mathrm{C}=0$ stretching frequencies in the IR spectrum are: $1695 \mathrm{~cm}^{-1}$ for the conjugated keto group in actinioerythrin, $1675 \mathrm{~cm}^{-1}$ for the same in violerythrin and $1750 \mathrm{~cm}^{-1}$ for the unconjugated keto group in violerythrin. The p.m.r. methyl signals of the gem dimethyl group occur at lower field than in the corresponding 6-rings.

An interesting reaction is that of actinioerythrin or violerythrin with weak alkali, whereupon lemon yellow hypophasic products are formed, which after acidification slowly revert to the dark blue violerythrin. The striking colour changes observed are given in Figure 29. Broken conjugation

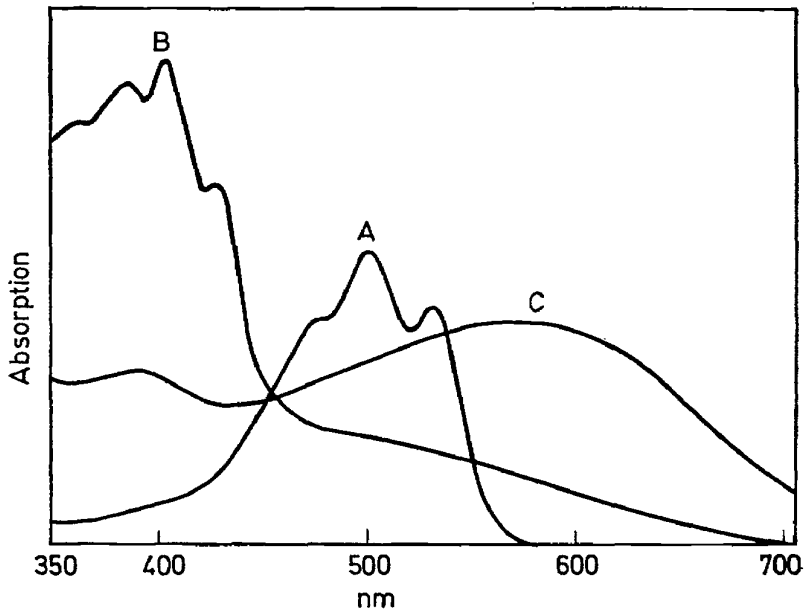

Figure 29. Spectral effect of alkali on actinioerythrin or violerythrin; arbitrary concentrations in ether solution: A actinioerythrin, B yellow epiphase following acidification of the yellow, alkaline hypophase, $\mathbf{C}$ extract $\mathbf{B}$ kept at room temperature.

on the aliphatic chain must be assumed in order to account for these spectral changes. A theory involving hydroxylation on the chain has been entertained. Alkali treatment of actinioerythrin presumably occurs (Figure 30) in analogous manner to that of astaxanthin ${ }^{92}$ esters via the $\alpha$-ketol, which in the absence of oxygen forms a deep-blue tetraenolate and in the presence of oxygen is autoxidized to violerythrin. From work by Kuhn and Sørensen ${ }^{92}$ hydrogen peroxide is known to be liberated on alkali treatment of astaxanthin. Violerythrin is not stable as such in the presence of base. The first step in the benzilic acid rearrangement is addition of $\mathrm{OH}^{-}$to a carbonyl group ${ }^{93}$ and it is conceivable that in this conjugated system that addition of $\mathrm{OH}^{-}$ may occur on the polyene chain to form hypophasic enolate salts of the type indicated, which on acidification become epiphasic as a strongly hydrogenbonded enolised $\alpha$-diketone, which on elimination of water gives violerythrin. The hypothesis will be subjected to further experimental studies.

Biogenetically (Figure 31) it is tempting to suggest that sea anemones produce their actinioerythrin from astaxanthin via a hypothetical ditriketone, which by benzilic acid rearrangement could give the $\beta$-keto-acid. This would easily decaroboxylate to actinioerythrol. This hypothesis derives 


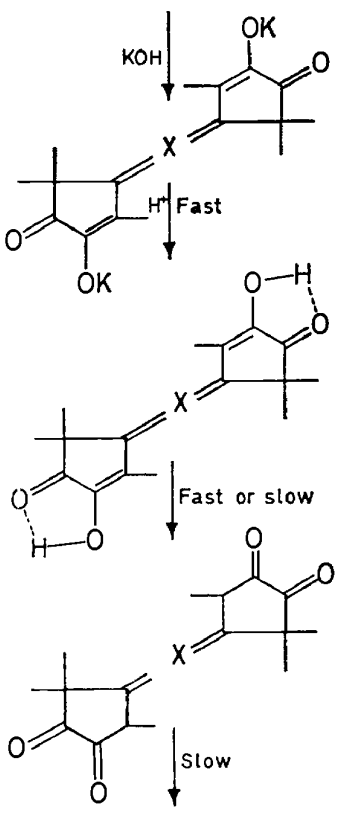<smiles>[Y]=C/C(C)=C/C(O)/C=C/C=C(C)\C=C\C=C(C)\C=C\C=C(/C)C(C)O</smiles><smiles>CC(/C=C/C=C(C)/C=C/C=C(C)/C=C/C=C(C)/C=C/C1CC(=O)C(C)C(=O)C1)=C\C=C1\C=C(CO)C(=O)C(=O)C1(C)C</smiles>

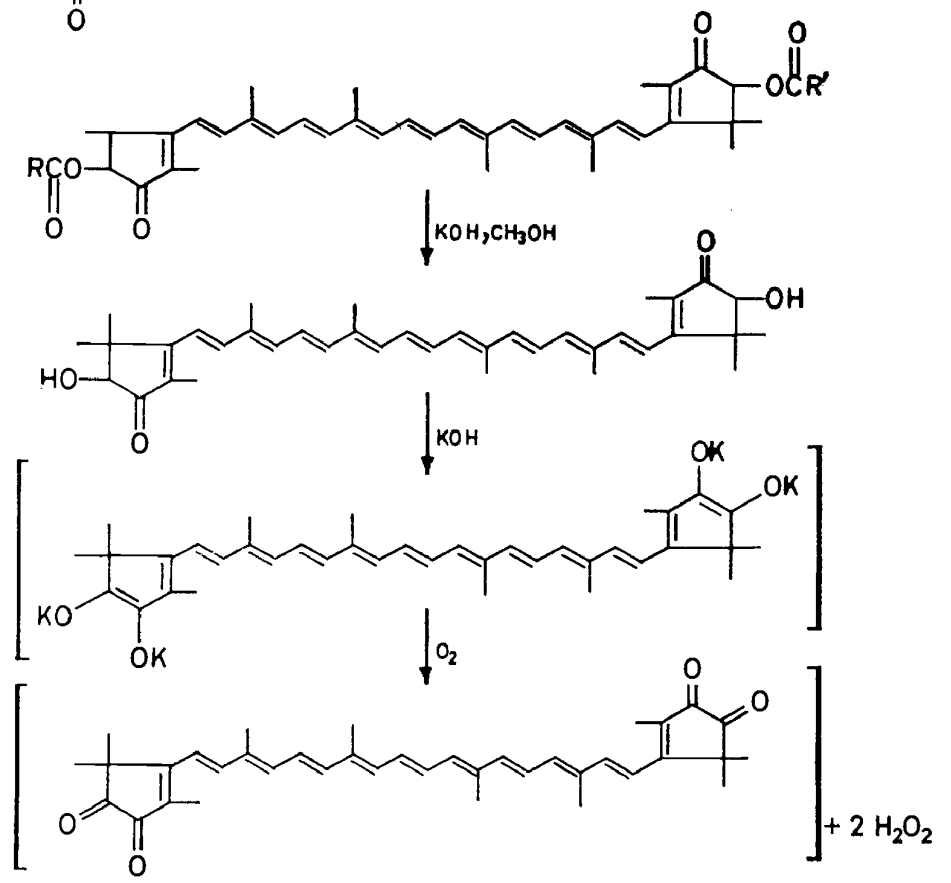

Figute 30. Possible structural interpretation of the effect of alkali on actinioerythrin and violerythrin ${ }^{89}$. 

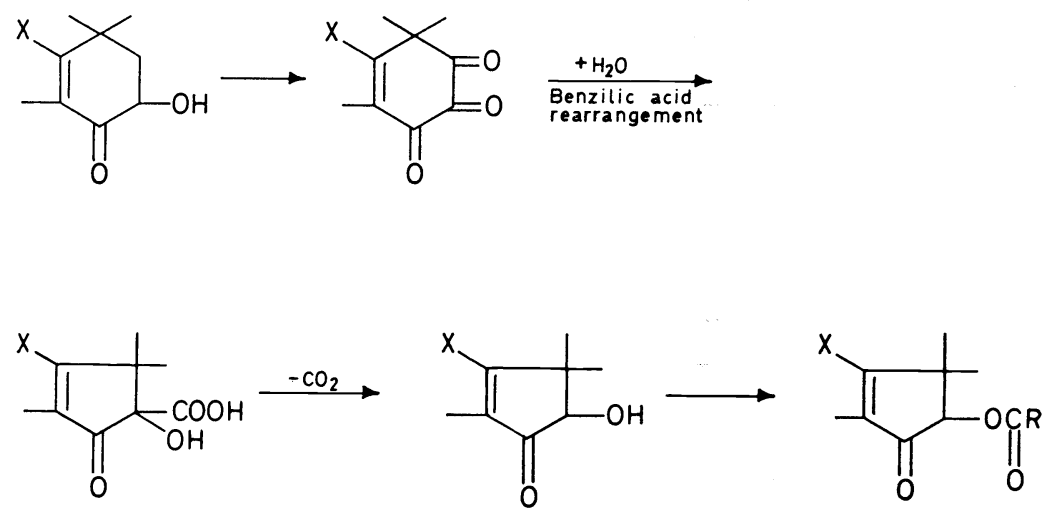

$X$ : polyene chain

Figure 31. Postulated biosynthesis of nor-carotenoids with ring contraction (actinioerythrin) ${ }^{\mathbf{8} 8}$.

some support from the fact that we have isolated minor carotenoid esters $\mathrm{X}$, which analogously to astaxanthin on saponification give the diosphenol astacin with two 6-rings ${ }^{89}$. An in vitro conversion of astacene to violerythrin has recently been reported by Weedon's group ${ }^{94}$. They employed manganous dioxide oxidation of astacene and assumed that the reaction occurs by benzilic acid rearrangement-analogous to the biosynthetic pathway suggested by us.

In order to investigate the biosynthesis of carotenoids in Actinia equina we have kept the sea anemones in an aquarium on a carotenoid-free diet for 10 months. However, contrary to earlier observations ${ }^{95}$ they maintain their mauve colour. Even the new progency develop to mauve individuals in the presence or absence of light. Proof for de novo synthesis of carotenoid in animals does not exist ${ }^{96}$, and it is premature, but tempting, to claim de novn synthesis from our experiment with the Norwegian variety of $A$. equina.

\section{CONGLUSION}

Although the tetraterpenes as represented by the carotenoids have no doubt shown less structural imagination than their lower-membered relatives, the sesqui-, di- and tri-terpenes, it is evident from the general research progress in the field, of which the work discussed represents a certain contribution, that the carotenoids have proved more numerous and less traditional in their structural pattern than previously considered.

I would like to emphasize the contribution from my collaborators-upon whose work much of this lecture is based. Arne Jorgen Aasen, Noël Arpin, George W. Francis, Sissel Hertzberg, Michael Kelly, Helge Kjosen, Sister M. Clare Markham, Sissel Norgaird and Owen B. Weeks joined one or several of the projects discussed.

$I$ would also like to acknowledge excellent collaboration with Docent K.Eimhjellen of the Department of Biochemistry at our University, Professor N. Pfennig at Institut für Mikrobiologie at the University in Göttingen, the mass spectrometry group of 


\section{STRUCTURE DETERMINATION OF NATURAL GAROTENOIDS}

Dr C. Enzell in Stockholm and Dr O. Isler's group at Hoffmann-La Roche in Basel. Financially our research has been supported by the last named firm and the Norwegian Research Council for Science and Humanities. Their support is gratefully acknowledged.

\section{References}

1 S. Liaaen-Jensen. J. Pure and Applied Chem. 14, 227 (1967).

2 T. W. Goodwin. Soc. Biol. Chemists, India: Souvenir 1955, 271.

3 S. Liaaen-Jensen, G. Cohen-Bazire and R. Y. Stanier. Nature 192, 1168 (1961).

4 S. Liaaen-Jensen. Bacterial Photosynthesis (Ed. H. Gest, A. San Pietro and L. P. Vernon), p. 19, Antioch Press, Yellow Springs, Ohio, 1963.

5 M. S. Barber, L. M. Jackman, P. S. Manchand and B. C. L. Weedon. J. Chem. Soc. C. 2166 (1966)

6 K. Schmidt, N. Pfennig and S. Liaaen-Jensen. Arch. Mikrobiol. 52, 132 (1965).

7 S. Liaaen-Jensen. Phytochem. 4, 925 (1965).

8 S. Liaaen-Jensen, G. Cohen-Bazire, T. O. M. Nakayama and R. Y. Stanier. Biochem. et Biophys. Acta 29, 477 (1958).

9 K. E. Eimjellen and S. Liaaen-Jensen. Biochim. et Biophys. Acta 82, 21 (1964).

10 L. M. Jackman and S. Liaaen-Jensen. Acta Chem. Scand. 18, 1403 (1964).

11 A. J. Aasen and S. Liaaen-Jensen. Acta Chem. Scand. 21, 2185 (1967).

12 A. J. Aasen and S. Liaaen-Jensen. Acta Chem. Scand. 21, 970 (1967).

13 S. Liaaen-Jensen, E. Hegge and L. M. Jackman. Acta Chem. Scand. 18, 1703 (1964).

14 S. Liaaen-Jensen. Acta Chem. Scand. 19, 1025 (1965).

15 K. Schmidt, S. Liaaen-Jensen and H. G. Schlegel. Arch. Mikrobiol. 46, 117 (1963).

16 S. Liaaen-Jensen. Acta Chem. Scand. 21, 961 (1967).

17 S. Liaaen-Jensen. Experientia. In press.

18 M. C. Khosla and P. Karrer. Helv. Chim. Adta 43, 453 (1960).

19 R. D. G. Cooper, J. B. Davis and B. C. L. Weedon. Proc. Chem. Soc. 5637 (1963).

20 K. E. Wilzbach and L. Kaplan. J. Am. Chem. Soc. 87, 4004 (1965).

21 A. W. Bergstahler, P.-L. Chien and M. O. Abdel-Rahman. J. Am. Chem. Soc. 86, 5281 (1964).

22 S. Liaaen-Jensen. Norw. J. Chem., Mining, Metallurgy 24, 27 (1963).

23 S. Liaaen-Jensen and K. Schmidt. Arch. Mikrobiol. 46, 138 (1963).

${ }^{24}$ G. W. Francis and S. Liaaen-Jensen. Acta Chem. Scand. To be published.

25 A. J. Aasen and S. Liaaen-Jensen. Acta Chem. Scand. 21, 371 (1967).

26 U. Schwieter, H. R. Bolliger, L. H. Chopard-dit-Jean, G. Englert, M. Kofler, A. König, C. v. Planta, R. Rüegg, W. Vetter and O. Isler. Chimia 19, 294 (1965).

27 C. R. Enzell, G. W. Francis and S. Liaaen-Jensen. Acta Chem. Scand. 22, 1054 (1968).

28 G. R. Enzell, G. W. Francis and S. Liaaen-Jensen. Acta Chem. Scand. 23, 727 (1969).

${ }^{29}$ L. Zechmeister. Cis-trans Isomeric Carotenoids, Vitamins A, and Arylpolyenes, Springer, Wien, 1962.

30 B. Ke, H. Kjøsen and S. Liaaen-Jensen. Biochim. et Biophys. Acta. In press.

31 S. Liaaen-Jensen and O. B. Weeks. Norw. J. Chem., Mining, Metallurgy 26, 130 (1966).

32 S. Liaaen-Jensen. Acta Chem. Scand. 21, 1972 (1967).

33 S. Liaaen-Jensen, S. Hertzberg, O. B. Weeks and U. Schwieter. Acta Chem. Scand. 22, 1171 (1968).

34 U. Schwieter and S. Liaaen-Jensen. Acta Chem. Scand. 23, 1057 (1969).

35 S. Liaaen-Jensen, O. B. Weeks, R. H. C. Strang and D. Thirkell. Nature 214, 379 (1967).

36 N. Arpin, G. W. Francis, S. Liaaen-Jensen and G. R. Enzell. Acta Chem. Scand. To be published.

37 G. W. Francis, N. Arpin and S. Liaaen-Jensen. Unpublished results.

38 S. Norgård, A. J. Aasen and S. Liaaen-Jensen. Acta Chem. Scand. In press.

39 M. Kelly and S. Liaaen-Jensen. Acta Chem. Scand. 22, 2578 (1968).

40 S. Liaaen-Jensen. Acta Chem. Scand. 14, 950 (1960).

41 D. F. Schneider and B. C. L. Weedon. J. Chem. Soc. C. 1686 (1967).

$42 \mathrm{M}$. Kelly, S. Norgård and S. Liaaen-Jensen. Acta Chem. Scand. In press.

43 C. R. Enzell and S. Liaaen-Jensen. Acta Chem. Scand. To be published.

44 S. Liaaen-Jensen. Acta Chem. Scand. 14, 953 (1960).

45 M. P. Starr and S. Saperstein. Arch. Biochem. 43, 157 (1953).

46 N. I. Krinsky. Anal. Biochem. 6, 293 (1963).

47 S. Hertzberg and S. Liaaen-Jensen. Acta Chem. Scand. 21, 15 (1967).

48 S. Hertzberg and S. Liaaen-Jensen. Phytochem. 8, 1259 (1969).

49 S. Hertzberg and S. Liaaen-Jensen. Phytochem. 8, 1281 (1969).

50 A. J. Aasen, G. W. Francis and S. Liaaen-Jensen. Acta Chem. Scand. 23. 2605 (1969).

$51 \mathrm{~S}$. Hertzberg and S. Liaaen-Jensen. Phytochem. 5, 557 (1966). 


\section{SYNNØVE LIAAEN-JENSEN}

52 S. Hertzberg and S. Liaaen-Jensen. Phytochem. 5, 565 (1966).

53 S. Hertzberg and S. Liaaen-Jensen. Phytochem. 6, 1119 (1967).

54 I. M. Heilbron and B. Lythgoe. J. Chem. Soc. 1376 (1936).

55 P. Karrer and J. Rutschmann. Helv. Chim. Acta 27, 1691 (1944).

56 A. J. Aasen and S. Liaaen-Jensen. Acta Chem. Scand. 20, 811 (1966).

57 J. D. Surmatis and A. Ofner. J. Org. Chem. 28, 2735 (1963).

58 N. Arpin and S. Liaaen-Jensen. Phytochem. 6, 995 (1967).

$59 \mathrm{O}$. Isler and U. Schwieter. Unpublished synthetic work.

${ }^{60}$ N. S. Bowman, D. E. Rice and B. R. Switzer. J. Am. Chem. Soc. 87, 4477 (1965).

61 M. L. Martin and G. J. Martin. Bull. Soc. Chim. France 2117 (1966).

${ }^{62}$ E. Hemmer and S. Liaaen-Jensen. Acta Chem. Scand. To be published.

${ }^{63}$ G. W. Francis, S. Hertzberg, K. Anderson and S. Liaaen-Jensen. Phytochem. In press.

64 P. Karrer and K. Miki. Helv. Chim. Acta 12, 985 (1929).

${ }^{65}$ K. Biemann, D. C. De Jongh and H. K. Schnoes. J. Am. Chem. Soc. 85, 1763 (1963).

${ }^{66} \mathrm{H}$. Kjösen and S. Liaaen-Jensen. Unpublished results.

67 A. J. Aasen and S. Liaaen-Jensen. Acta Chem. Scand. 19, 1843 (1965).

${ }^{68}$ N. Arpin and S. Liaaen-Jensen. C. R. Acad. Sci. Paris Serie D 265, 1083 (1967).

${ }^{69}$ N. Arpin and S. Liaaen-Jensen. Bull. Soc. Chim. Biol. 49, 527 (1967).

${ }^{70}$ N. Arpin, G. W. Francis and S. Liaaen-Jensen. Unpublished results.

71 M. C. Markham and S. Liaaen-Jensen. Phytochem. 7, 839 (1968).

72 L. Zechmeister and L. v. Cholnoky. Ber. 69, $422(1936)$.

${ }^{73}$ L. v. Cholnoky and J. Szabolcs. Tetrahedron Letters 1931 (1968).

${ }^{74} \mathrm{M}$. Kelly and S. Liaaen-Jensen. Unpublished results.

75 A. Stabursvik. Acta Chem. Scand. 8, 1305 (1954).

76 H. Kjøsen and S. Liaaen-Jensen. Phytochem. 8, 483 (1969).

77 N. Arpin and S. Liaaen-Jensen. Phytochem. 8, 185 (1969).

78 A. K. Mallams, E. S. Waight, B. C. L. Weedon, D. J. Chapman, F. T. Haxo, T. W. Goodwin and D. M. Thomas, Chem. Commun. 301 (1967).

79 S. A. Campbell, A. K. Mallams, E. S. Waight, B. C. L. Weedon, M. Barbier, E. Lederer and A. Salaque. Chem. Commun. 941 (1967).

${ }^{80}$ K. Aitzetmüller, W. A. Svec, J. J. Katz and H. H. Strain. Chem. Commun. 32 (1968).

81 H. v. Euler and H. Hellström. Z. physiol. Chem. 222, 89 (1934).

82 N. A. Sørensen, S. Liaaen-Jensen, B. Bördalen, A. Haug, C. Enzell and G. Francis. Acta Chem. Scand. 22, 344 (1968).

83 G. W. Francis and S. Liaaen-Jensen. Acta Chem. Scand. To be published.

${ }^{84}$ J. L. H. Allan, G. D. Meakins and M. C. Whiting, J. Chem. Soc. 1874 (1955).

85 P. Karrer and E. Jucker. Carotinoid. Birkhäuser, Basel, 1948.

86 E. Lederer. Compt. Rend. Soc. Biol. 113, 1391 (1931).

87 J. M. Heilbron, M. Jackson and R. N. Jones. Biochem. J. 29, 29 (1935).

88 S. Hertzberg and S. Liaaen-Jensen. Acta Chem. Scand. 23, 185 (1969).

89 S. Hertzberg, S. Liaaen-Jensen, G. R. Enzell and G. W. Francis. Acta Chem. Scand. In press.

90 E. Dane, J. Schmitt and C. Rautenstrauch, Ann. 532, 29 (1937).

91 S. Liaaen-Jensen. Acta Chem. Scand. 19, 1166 (1965).

92 R. Kuhn and N. A. Sörensen. Ber. 71, 1879 (1938).

93 W. A. Bonner and A. J. Castro. Essentials of Modern Organic Chemistry, Reinhold, New York, 1965 , p. 332.

94 R. Holzel, A. P. Leftwick and B. C. L. Weedon. Chem. Commun. 128 (1969).

95 M. and R. Abeloos-Parize. C. R. Soc. Biol. 94, 560 (1926).

96 T. W. Goodwin. In M. Florkin and B. T. Scheer. Chemical Zoology Vol. II. Poryfera, Coclenterata and Platyhelminthes, Ch. 2. Academic Press, London (1968). 